\title{
Pathophysiology of ischemic reperfusion injury and the molecular targets involved in amelioration of brain injury by herbal medicine
}

\author{
Ibrahim Mohammed Badamasi',A-F \\ ${ }^{1}$ Bayero University, Kano, Nigeria \\ A - Research concept and design, B - Collection and/or assembly of data, C - Data analysis and interpretation, \\ $D$ - Writing the article, E - Critical revision of the article, F- Final approval of article
}

Ibrahim Mohammed Badamasi. Pathophysiology of ischemic reperfusion injury and the molecular targets involved in amelioration of brain injury by herbal medicine.J Pre-Clin Clin Res. 2021; 15(2): 87-99. doi: 10.26444/jpccr/134526

\begin{abstract}
Introduction and objectives. A number of preclinical evaluations of stroke treatment with herbal medicine (HM) have been reported. The aim of the current review was to highlight the pathophysiology of stroke and review the pre-clinically identified molecular mechanisms of HM treatment.

Materials and method. Only 32 articles published in the English language were accessible on Google scholar describing the treatment and mechanistic processes of HM in animal models of stroke, as well as human clinical trials, and were reviewed in this study.

Results and discussion. Suboptimal $\mathrm{Na}+/ \mathrm{K}+$ ATPases pump activity, actions of microglia cytokines that increase the level intracellular adhesion molecules-1 (ICAM-1) which promote WBC extravasation with associated increased in matrix metalloproteinase (MMP) activity (digest basement-membranes), explains edema and apoptosis/inflammation. Altered conductivity in injured neurons with compensatory increase in glutamate release that overwhelms the regulatory glial glutamate transporter 1, and thus peaks the level of glutamate to an excitotoxin leve, promotes neuronal death. Glutamate activity on NMDAR promotes oxidative stress, lipid peroxidation and release/influx of Ca2+ that causes apoptosis. The molecular targets involved in the treatment for stroke by HM promote anti-apoptotic/anti-inflammation, anti-oxidation, angiogenesis, neurogenesis, anticoagulation/fibrinolysis effects and optimal metabolism. Different HM promotes the activities of tissue plasminogen activator, haemeoxygenase 1, Neutrin-1, brain derived neurotropic factor (BDNF) and mitogen-activated protein kinase (MAPK).

Conclusion. The pathophysiology of stroke and the preclinical targets on which HM act to ameliorate them were identified which could serve as a focus for research on the development of effective treatment for stroke.
\end{abstract}

\section{Key words \\ brain, molecular, efficacy, stroke, complimentary medicine}

\section{INTRODUCTION}

Brain stroke is commonly characterized by a region of cell death attributed to ischemic changes, as well as an active adjacent area of brain tissue regeneration called a penumbra $[1,2]$. A high level of vasculature as well as early re-establishment of functional microvasculature around the stroke region facilitate quick and optimal recovery of neuronal cells after stroke [3]. The reperfusion of the ischemic region, which is apparently necessary to salvage the neuronal cells from irreversible damage, has also been implicated as a major source of injury to the brain [4]. Increased reactive oxygen species, dysregulation of calcium hemostasis, microvascular dysfunction with loss of blood flow, exaggeration of inflammatory response, and slow-onset apoptotic cell death contributes to reperfusion injury after ischemia [5]. There are numerous possible causes of ischaemia reperfusion injury, such as trauma, hypovolemic shock with resuscitation, vascular reflow after contraction, percutaneous transluminal coronary angioplasty, thrombolysis treatment and organ transplantation [6].

Address for correspondence: Ibrahim Mohammed Badamasi, Bayero University, Kano, Nigeria

E-mail: badamasi_mohammedibrahim@yahoo.com

Received: 23.10.2020; accepted: 17.03.2021; first published: 07.04.2021
Most conventional therapeutic agents used for the management of ischemic stroke have single mechanisms of action geared towards revamping, as well as maintaining the blood flow, in order to optimize the functioning of neurons and not necessarily the functions of other brain supportive structures $[7,8,9]$. Tissue plasminogen activator (tPA) as well as mechanical thrombectomy are the only treatment approved by the FDA in the USA for the management of acute ischemic stroke to reestablish blood flow [10]. The narrow therapeutic window for tPA, the short time period (3-4.5 hours) within which its administration potentially promotes neuronal recover, as well as the serious side-effects in many patients following its us, have limited its use among of patients eligible for treatmentwith tPA $[11,12,13,14]$. Medications with multi-target capabilities for ameliorating/reversing individual pathological components of an entire framework of a complex pathology such as strok, are potentially better fitted for achieving a remarkable outcome compared to medications with single-target remedy approaches to such pathology [15].

Herbal medicines (HM) are known to have multiple targets through which they promote the hemostasis of the entire neurovascular units comprising of neurons, endothelial cells, astrocytes and basal lamina $[12,16]$. Therefore, the HM have great potentials for attenuating all the facets of distortions 
that are vital for the development of detrimental effects of stroke, and hence they are potentially very promising candidates for supporting standard stroke treatment. A double-blind, placebo-controlled and randomized clinical trial identified that the use of Gingko biloba at $120 \mathrm{mg} /$ day for four months during the post-stroke period, not only hastened recovery but also decreased the scores according to the National Institute of Health Stroke Scale (NIHSS) [17]. A meta-analysis and double-blind, placebo-controlled and randomized clin, with associated optimal functional recovery $[18,19]$.

\section{OBJECTIVES}

A detailed update of the pathophysiological processes for the development of strok, as well as a systematic review of the pre-clinically identified mechanisms involved in the activity of HM for stroke management, were the main focus of the study. Highlighting the molecular mechanisms of actions of these $\underline{\mathbf{H M}}$ could serve as a nidus for identifying clinically-druggable targets for new medicines that are both safe and effective for the management of stroke. Figure 1 shows the general pathophysiological features associated with cerebral ischemic hypoxic injury to the brain, as well as the mechanism of activities of HM that may resolve/attenuate the different segments of the pathology.

\section{MATERIALS AND METHOD}

The processes adopted for the current review involved a thorough search of the Google scholar data base using search such word as 'neurogenesis' and 'herbs'. The criteria included that the articles must be of either human, animal or in vivo studies, and must be related to the role of an HM in stroke and/or neurogenesis. The scope of the articles may include evaluation of the modulatory effect of HM on stroke patients and /or stroke model, and therefore be related to preclinical or clinical studies. A total of 6,040 articles identified were by using the search words were evaluated. The search out-put was arranged as 10 article titles per page for a total of 100 pages, and all articles were evaluated. The titles relevant to the proposed review were further assessed by reading the abstracts and the whole articles (32) and thus identified as fulfilling the criteria for inclusion in the current review (Fig. 2).

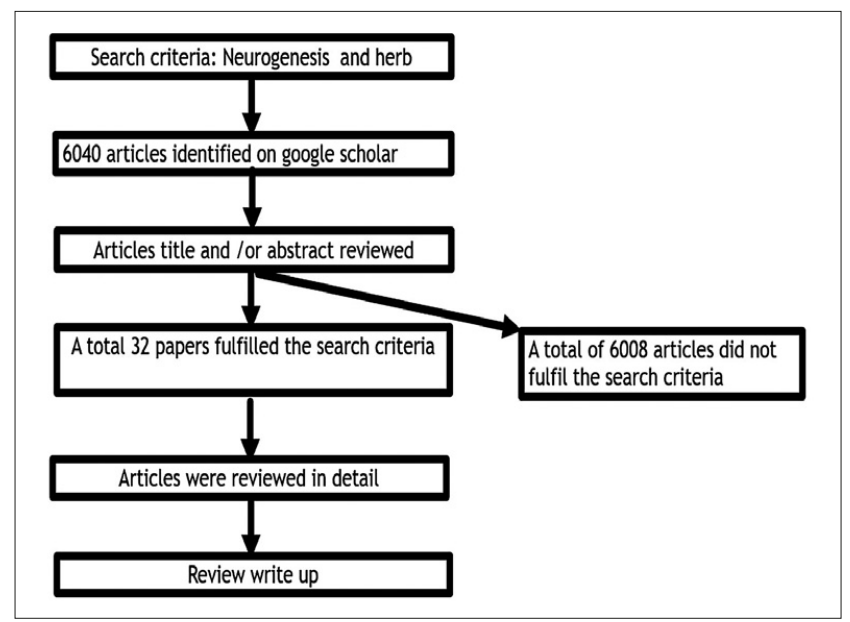

Figure 2. Step-by-step methodology involved in the identification and selection of reviewed articles in the current review

Pathophysiology of stroke identified in
the literature
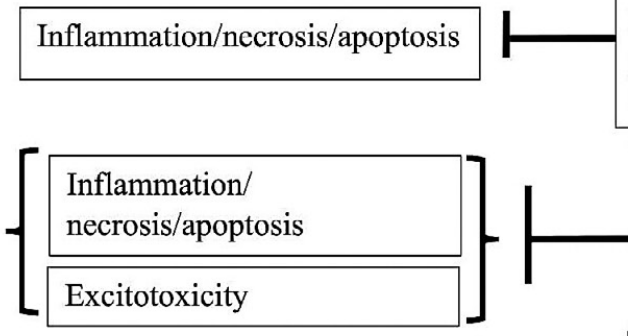

Oxidative stress and lipid peroxidation

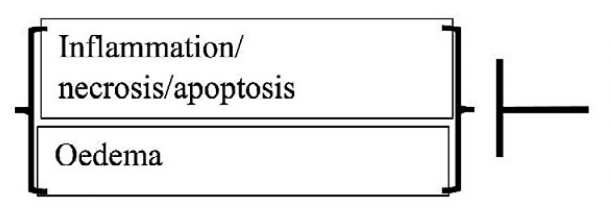

Mechanism of actions for herbal medications elucidated in literature via which Pathophysiology of stroke are ameliorated

Neurogenesis. 1. Migration and survival of neurons: netrin-1, DCC and UNC5B; SDF1 and CCX4; 2. Neuronal growth and differentiation: ERK2) a key component of the MAPK signalling pathway, of GAP-43, Wnt/ $\beta$-catenin pathway (including DCX, Fgfr3, Cttnbp2, Rorb, Abi2 and Miat, Ptprf, Ift172 and Nfib genes). cAMP/PKA/CREB/Brain derived growth factor (BDNF).

Antiapoptotic/ Antiinflammation. Optimization of calcium levels. Decreases the level of Bcl-2; TLR/MyD88; MGLR-1; Aquaporin 4; as IL$1 \beta$, IL-6, TNF- $\alpha$; MEK/ERK/p90RSK/Bad signalling pathway Increased: nAChR $\alpha$ /phosphatidylinositol 3-kinase (PI3K)/ Akt/ GSK3及

Antioxidation. 1.Hemeoxygenase 1(HO1): 2. Hypoxia inducible factor $1 \alpha$ $(\mathrm{HIF}-1 \alpha)$ :_3. Glial fibrillary acidic protein (GFAP) and S-100B; 4. Low ROS

Anticoagulation /fibrinolysis effect. Decrease: aggregation of platelet; plasminogen activator; Increase: endogenous $\mathrm{PAr}$, as well as

Metabolism: Increased NAA/Cr ratio; Decreased $\mathrm{Cho} / \mathrm{Cr}$

Angiogenesis: Increased activity of : HIF-1 $\alpha$; AKT/mTOR/ HIF-1 $\alpha$, ERK1/2 SIRT1/ Vascular endothelial growth factor (VEGF) /cGMP pathway; ICAM-1, VCAM-1 and E-selectin; Ang1.

Figure 1. Overview of the pathophysiology of stroke and molecular targets on which herbs have been elucidated to act 


\section{DESCRIPTION OF THE STATE OF KNOWLEDGE}

Pathophysiology of stroke. The events that culminate in the pathology of stroke are derived from both the initial insult of cerebral ischemia-hypoxia and those of the reactive responses following cerebral reperfusion that are aimed at repairing the damaged tissue (Fig. 3, 4). Cerebral ischemia/reperfusion leads to increased levels of free radical, excitatory glutamate, and intracellular calcium overload, as well as inflammation and its products, which release active matrix metalloproteinase (MMP), as well as dissolution of the basement membrane which disrupts the integrity of the blood brain barrier (BBB) with the risk for cerebral edema and hemorrhage $[20,21,22]$. The BBB is a barrier against the admixture of extracellular fluid of CNS with the blood in the blood vessels of the brain [23]. Tight junctions between endothelial cells are vital constituents of the BBB. Claudins, occludin, junctional adhesion molecus, as well as other cytoskeletal proteins, are key constituents of tight junctions and can potentially be affected by physiological and pathological conditions [24, $25,26,27]$. Loss of BBB, Cerebral edema and hemorrhagic transformation of an ischemic stroke, are a nidus for the exacerbation of brain injury [27]. Swelling of the brain caused by edema can increase intracranial pressure, with a sustained ischemic injury and formation of a hernia [28].

\section{KEY PATHOPHYSIOLOGICAL EVENTS OF STROKE}

Inflammation. One hour after cerebral ischemia, a progressive increase in the permeability of the brain blood vessels begins and usually last for a day. This disruption of the $\mathrm{BBB}$ permits proteins as well as fluid to enter the cerebral extracellular space with associated vasogenic edema and brain injury (Fig. 3) [28, 29]. Sterile inflammation is triggered by the cerebral ischemic injury that activates brain astrocytes and microglia cells (key regulators of brain endothelial cell) and promote the formation of inflammatory cytokines such as interleukin one-beta (IL-1 $\beta$ ), interleukin -six (IL-6), and tissue necrosis alpha (TNF- $\alpha$ ) that exacerbate the inflammation further $[23,30,31,32]$. TNF- $\alpha$ promote the expression of intracellular adhesion molecules -1 (ICAM1), which accelerates the adhesion and extravasation of leukocyte into the region of brain injury [23]. The brain injury also promotes the infiltration of macrophages and leukocytes which also promote the disruption of BBB [23]. The leucocyte dependent change from transient to persistent disruption of the BBB-tight junction protein orchestrated by neutrophilderived neurovascular metalloproteinase-9 (MMP-9), is key in the worsening of Ischemic brain injury[6]. It is pertinent to note that elevated levels of IL- $1 \beta$, IL- 6 , and TNF- $\alpha$ play a central role in post-stroke inflammation induced neuronal death (Fig. 3) [12]. Apoptotic cell death may also be elicited by the activities of these pro-inflammatory cytokines which can induce NF-KB nuclear translocation with elevation of P53-upregulated modulator of apoptosis (PUMA) (Fig. 3). When p53 is released from $\mathbf{B}$-cell lymphoma-extra large $\left(\mathrm{Bcl}-\mathrm{X}_{\mathrm{I}}\right)$ by activated PUMA, it can activate Bax and results in apoptosis within the infarcted hemisphere (Fig. $3,4)[33]$.

Excitotoxicity. Excessive glutamate within the brain extracellular space is common following cerebral hypoxiaischemic injury and it serves as an excitotoxin which promotes slow onset of neuronal death $[34,35]$. Excess glutamate is usually removed by glial glutamate transporterl (GLT-1), and is therefore responsible for maintaining the glutamate levels below neurotoxic levels (Fig. 4) [36]. In preclinical studies, the regions of the brain that were observed to have increased expression of GLT-1 after hypoxia-ischemic injury (such as Cornu Ammonis-three (CA3) of the hippocampus, show lower levels of apoptotic neuronal death when compared to those regions without an increase in GLT-1 (such as Cornu Ammonis - one and two (CA1 and CA2) of the hippocampus)

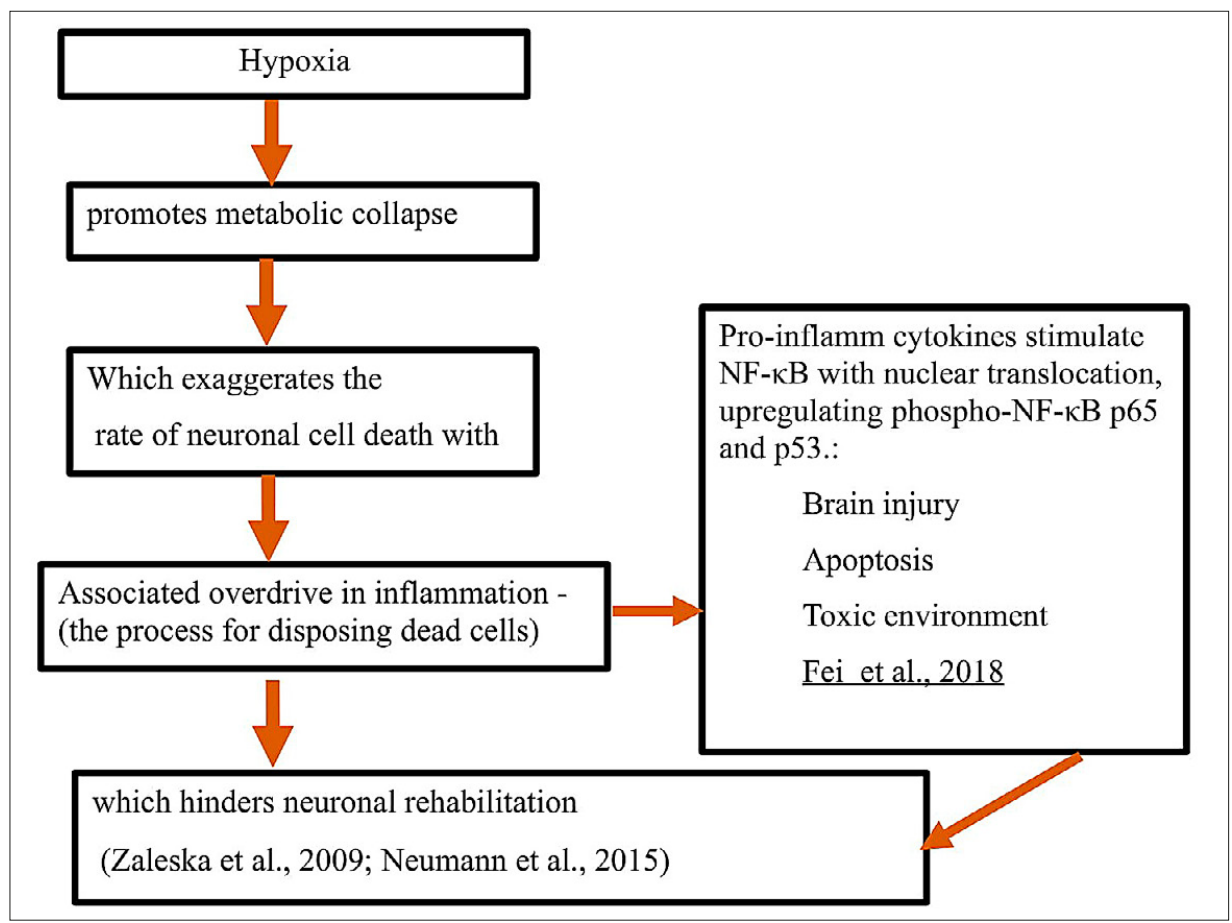

Figure 3. Pathophysiology of stroke in the current review 


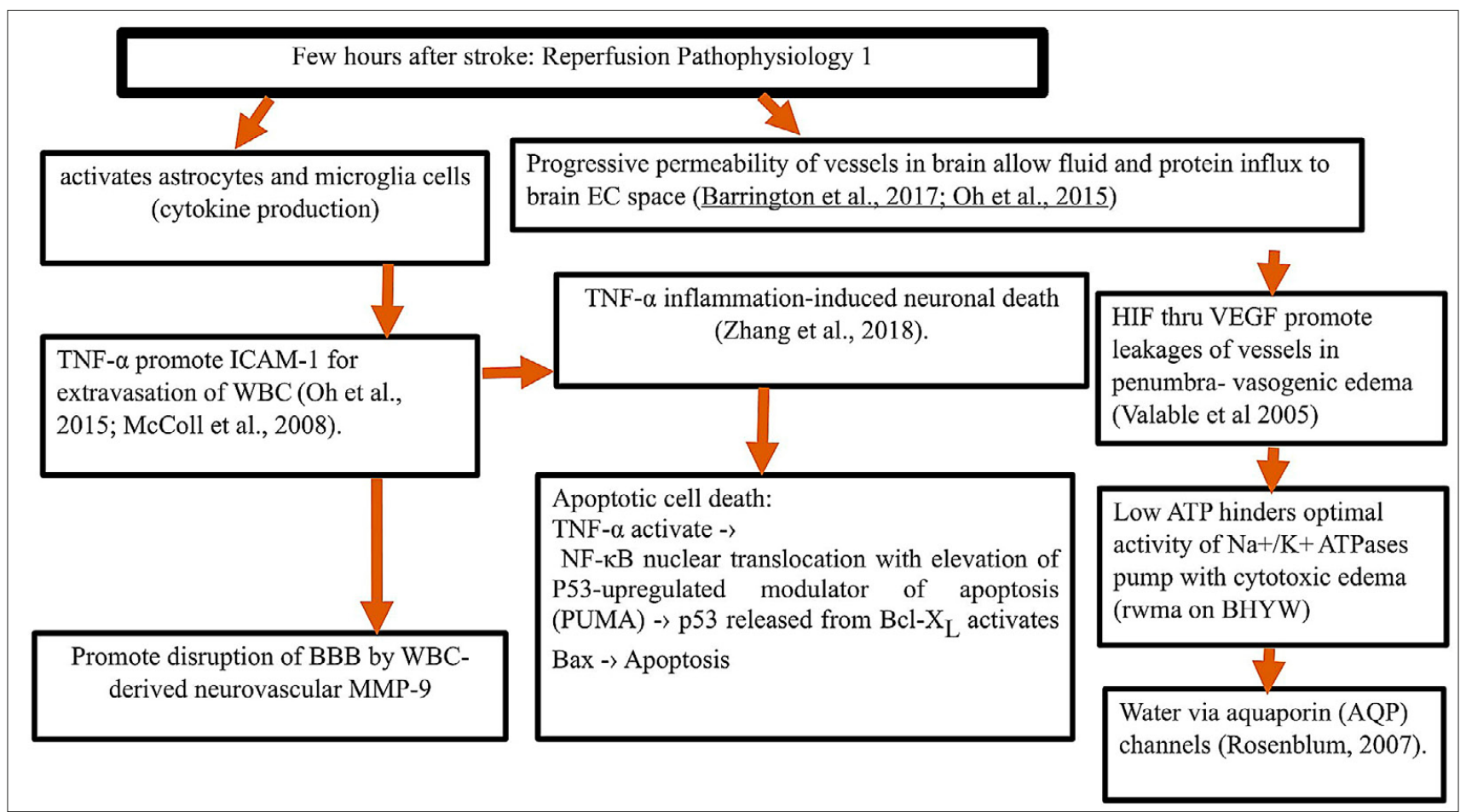

Figure 4. Events that occur few hours after stroke. Reperfusion pathophysiology 1

[37]. Excessive levels of potassium and calcium have also been reported to be promoters of poor neuronal excitability as well as an increase in the death of neurons via apoptosis $[5,38]$. The degradation of the intracellular homeostasis for calcium involves a number of cellular factors, such as depletion of ATP following ischemic - hypoxic insult to cerebral tissue. The depleted ATP renders sodium ion - potassium-ionAdenosine triphosphatase $\left(\mathrm{Na}^{+}, \mathrm{K}^{+}\right.$-ATPase $)$enzyme which regulates membrane ionic concentration highly incapacitated with associated persistent depolarization, as well as the opening of voltage-gated calcium channels (VGCCs) [39]. The ischemic-mediated increase in the release of glutamate (excitatory neurotransmitters) associated with activation of a-amino-3-hydroxy-5-methyl-4-isoxazolepropionic acid (AMPA) receptors, further depolarizes the membrane. It also increases the activation of N-methyl-D-aspartate receptor (NMDAR) which promotes nicotinamide adenine dinucleotide phosphate (NADPH) oxidase or mitochondriadependent reactive oxygen species (ROS) generation, with release of stored intracellular $\mathrm{Ca}^{2+}$ as well as influx of more $\mathrm{Ca}^{2+}$ via transient receptor potential melastatin (TRPM) channels (Fig. 4) [40, 41]. Calcium permeable acidsensing ion channel la (ASICla) has also been identified that may allow the influx of calcium following acidulation changes associated with cerebral ischemic hypoxic injury (Fig. 5) [42].

Oxidative stress and lipid peroxidation. The high risk of oxidative stress for the brain tissue is due to its high rate of oxidative metabolic activity with associated high rate of ROS production. Its high content of polyunsaturated fatty acid, low levels of antioxidants and poor resilience to damage, repair and replication of neuron, also contribute to its high risk of oxidative stress (Fig. 6) [43]. Generally, oxidative stress and lipid peroxidation are closely associated with ROS (Superoxide and hydroxyl radicals) which act as a potent destroyer of membrane via lipid peroxidation. High levels of lipid peroxides are reported in brain and muscle following ischemia-reperfusion injuries $[44,45]$.

Edema. A common response to ischemia or hypoxia in the brain involves the production of a hypoxia inducible factor [46]. Downstream genes encoding erythropoietin, vascular endothelial growth factor (VEGF) and glucose transporte, usually mediate the activity of HIF [47]. VEGF is rapidly expressed in the penumbra of brain ischemia region and promotes leakages of vessels as well as activation of MMP-9. The overall activity of hypoxia inducible factor $1 a$ (HIF), as well as its downstream proteins, are related to the development of a vasogenic edema in the early stages after ischemic stroke (Fig. 4).

Direct transportation of water into cells via aquaporin (AQP) channels can also lead to cell edema in the presence of an intact $\mathrm{BBB}$ [48]. The epithelial sodium channel $(\mathrm{ENaC})$ has also been reported to play a central role in the regulation of fluid balance in the cerebral tissue $[49,50]$. Failure of the $\mathrm{Na}+$ / $\mathrm{K}+$ ATPase pump after the loss of adenosine triphosphatase (ATP) associated with ischemia/hypoxia, may underlie the development of cytotoxic edema mediated through the $\mathrm{ENaC}$ (Fig. 4) [44].

Molecular targets involved in the herbal medicine treatment for stroke. Figure 1 shows the overview of the various mechanism of action of herbal medicine that for many years have played a central role in the management of stroke. The key mechanisms essentially include either an elevation or decrease in important direct or indirect mediators for cerebral ischemic injury. The key mechanism highlighted in Figure 1 include: antioxidation; neurogenesis; anticoagulation /fibrinolysis; angiogenesis and metabolism related processes. 


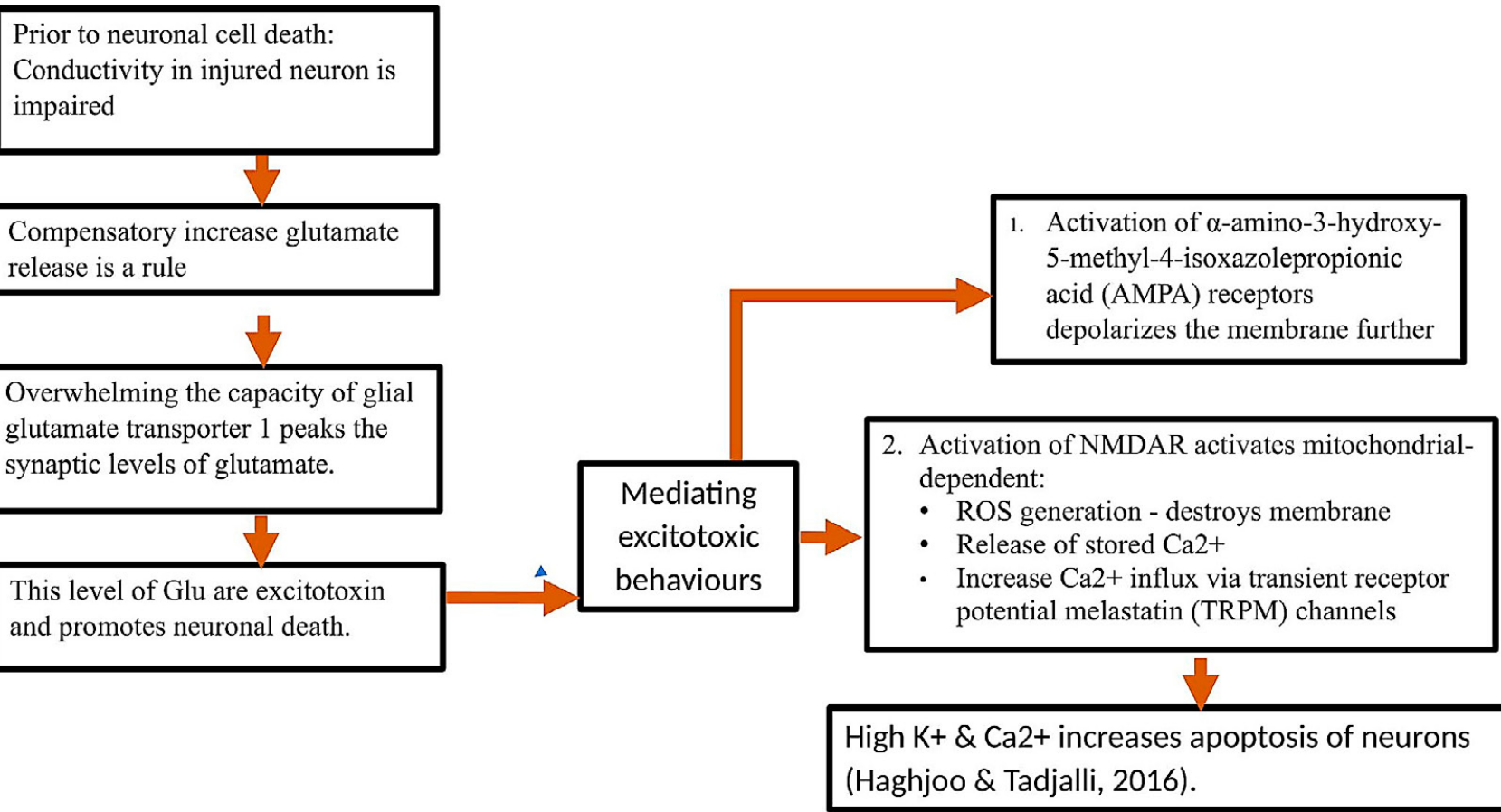

Figure 5. Events that occur prior to neuronal death. Reperfusion pathophysiology 2

Antioxidation - Hypoxia inducible factor 1a. A number of antioxidatio-related features have been identified in the mechanisms of action for herbal medicines that promotes resolution of cerebral ischemic injury in the literature. Hypoxia inducible factor $1 \alpha$ (HIF-1a): the activity of hypoxia inducible factor $-1 \alpha$ (HIF-1 $\alpha$ ) is mediated mainly through the activities of downstream genes of erythropoietin, vascular endothelial growth factor (VEGF), CCXR4, SDF-1 and glucose transporter $[47,51]$. Its activit, as well as the activities of the genes that it enhances (especially those of VEGF, and chemokine receptor type 4 (CCXR4 / Stromal Cell Derived Factor 1 (SDF-1)) promote angiogenesis [51]. There are studies that implicate the activity of HIF-1/VEGF as well as ENac in the development of edema following cerebral ischemic stroke through vascular leaks and MMP-9 activation, which can potentially worsen the cerebral injury $[50,52]$. It has also been directly attributed with a damaging effect on basement membrane, thereby promoting sterile inflammation as well as leakage of the BBB with an increased risk for edema (Fig. 5) [53, $54,55]$. The conundrum regarding the activity of HIF-1 $\alpha$ as to whether it is beneficial or deleterious, has been evaluated and the findings suggest that its detrimental inflammatory role after cerebral ischemia is associated with its early post-stroke peaking (hours after stroke, while its peaking after two to six days following stroke is beneficial [56]. Therefore, the HM such as Buyang Huanwu Decoction (BHD); Huatuo Zaizao pill (HZP) that can optimize the stimulatory activity of HIFla on the downstream genes involved in the angiogenesis pathway, are of immense potential benefit in the treatment of stro, especially when prescribed after the day of insult (Fig. 4).

Antioxidation - Hemeoxygenase 1 (HO1). This is an antioxidant enzyme primarily involved in the breakdown of heme. Its activity is optimal under stressful conditions, including hypoxic / ischemic injuries to the brain, which indicates a potential role for the enzyme in ameliorating stroke related neuronal pathology $[57,58,59]$. There are studies reporting an increased expression of vascular endothelial growth factor (VEGF) and a collapse in response mediator protein 2 (CRMP2) (vital for neuronal development), mediated by an elevated level of $\mathrm{HO} 1$ antioxidant activity $[60,61]$. Therefore, HO1 antioxidant activity promotes angiogenesis via VEGF as well as neuronal development and outgrowth via CRMP, which is a mechanism via which some HM especially EGb 761 of G. biloba promote neuronal wellbeing (Fig. 6) [62, 63].

Antioxidation - Decreased production of ROS. Attenuation of the production of superoxide anion (O2-), malondialdehyde (MDA) and glutathione peroxidase (GSH-Px) by HM also ameliorates the degree of neuronal damage reported following brain I/R injury. This protective effect against ROS and its activity is completely lost following attenuation of the Toll-like receptor/ Myeloid differentiation primary response 88 (My88) pathway (Fig. 8) [64].

Neurogenesis. Proliferation, migration and differentiation of neuronal stem cells (NSC) are the key activities that characterize neurogenesis (Fig. 7) [65]. Neurogenesi, as well as axonal remodeling, usually occur in the subventricular zone (SVZ) of the lateral ventricle following stroke or trauma; however, the normal endogenous neurogenesis is usually insufficient to ensure adequate functional recovery [66, 67]. Thus, HM such as Danshen-Chuanxiong-Honghua (DCH), Ruyi Zhenbao (RZ), Xijiao Dihuang Decoction (XDD) and extract of Ginkgo biloba 761 (EGb 761) that promote neurogenesis can play a vital role in accelerating the neurogenesis process to a correspondingly optimal level for recovery from I/R injury (Fig. 7).

Migration and survival of neurons. Increased expression of netrin-1 and its associated receptors (DCC and UNC5B) 


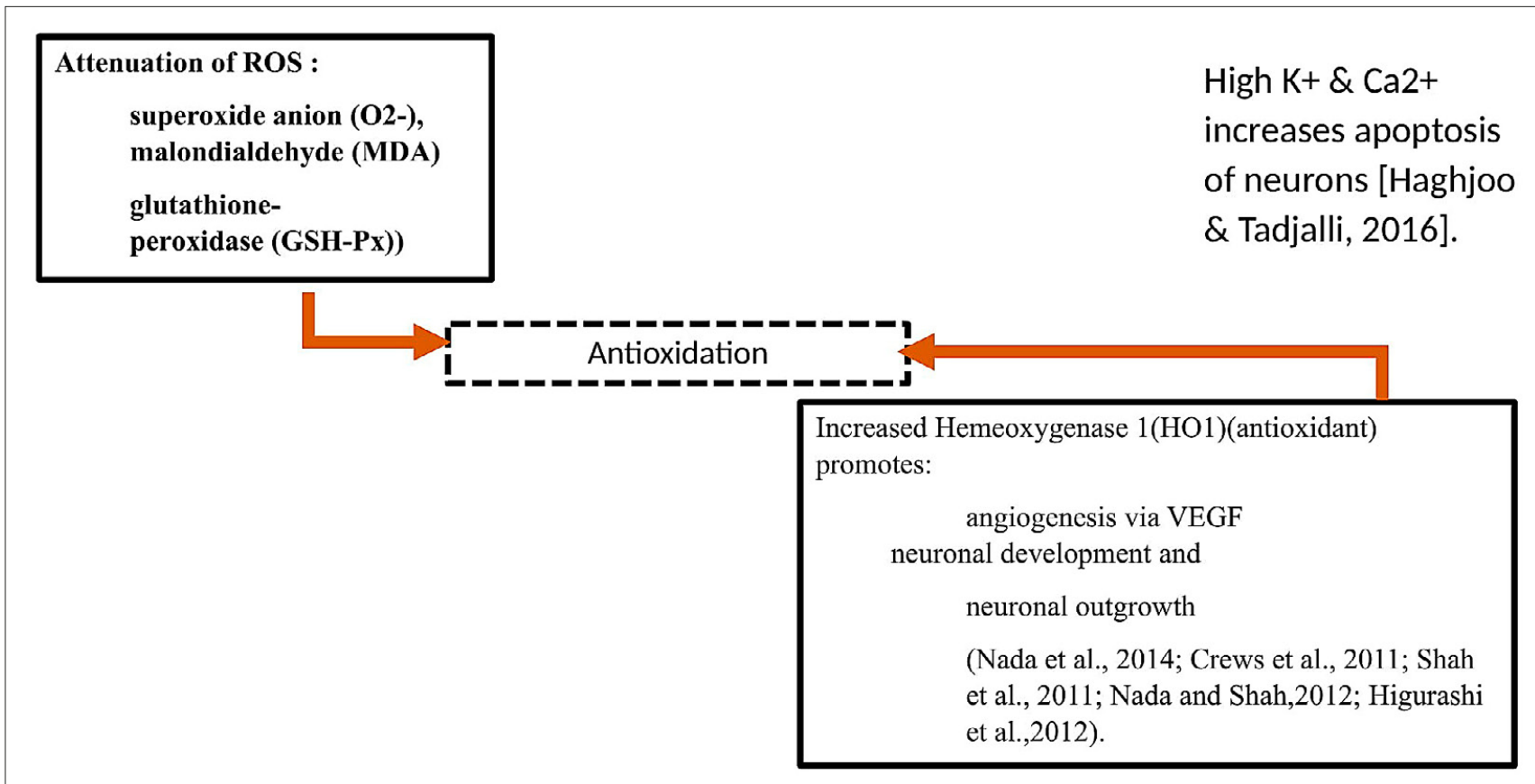

Figure 6. Molecular targets involved in the herbal medicine treatment for stroke (MTHM) via anti oxidation

promotes the activities of axons as well as the increased expression of stromal cell derived factor1(SDF1) and chemokine receptor type 4 (CCX4) which have also been associated with more stem cells in the penumbra $[68,69]$. Therefore, these targets mediate taxis of neural stem cells (NSC) to the region of the penumbra and $\underline{\mathbf{H M}}$, such as EGb 761, that upregulate them will putatively promote NSC migration into the penumbr, as well as ameliorate the neuronal loss as site of I/R injury (Fig. 7).
Neuronal growth and differentiation. Increased expression as well as activity of extracellular signal regulated kinase 2 (ERK2, a key component of the mitogen-activated protein kinase (MAPK) signalling pathway which promote neuronal growth and differentiation in the ischemic area, has been reported [70, 71, 72, 73, 74, 75]. Another mechanism of action for herbal therapy associated with improvement of neuronal integrity following stroke, involves a post-stroke increased expression of growth associated protein 43 (GAP-

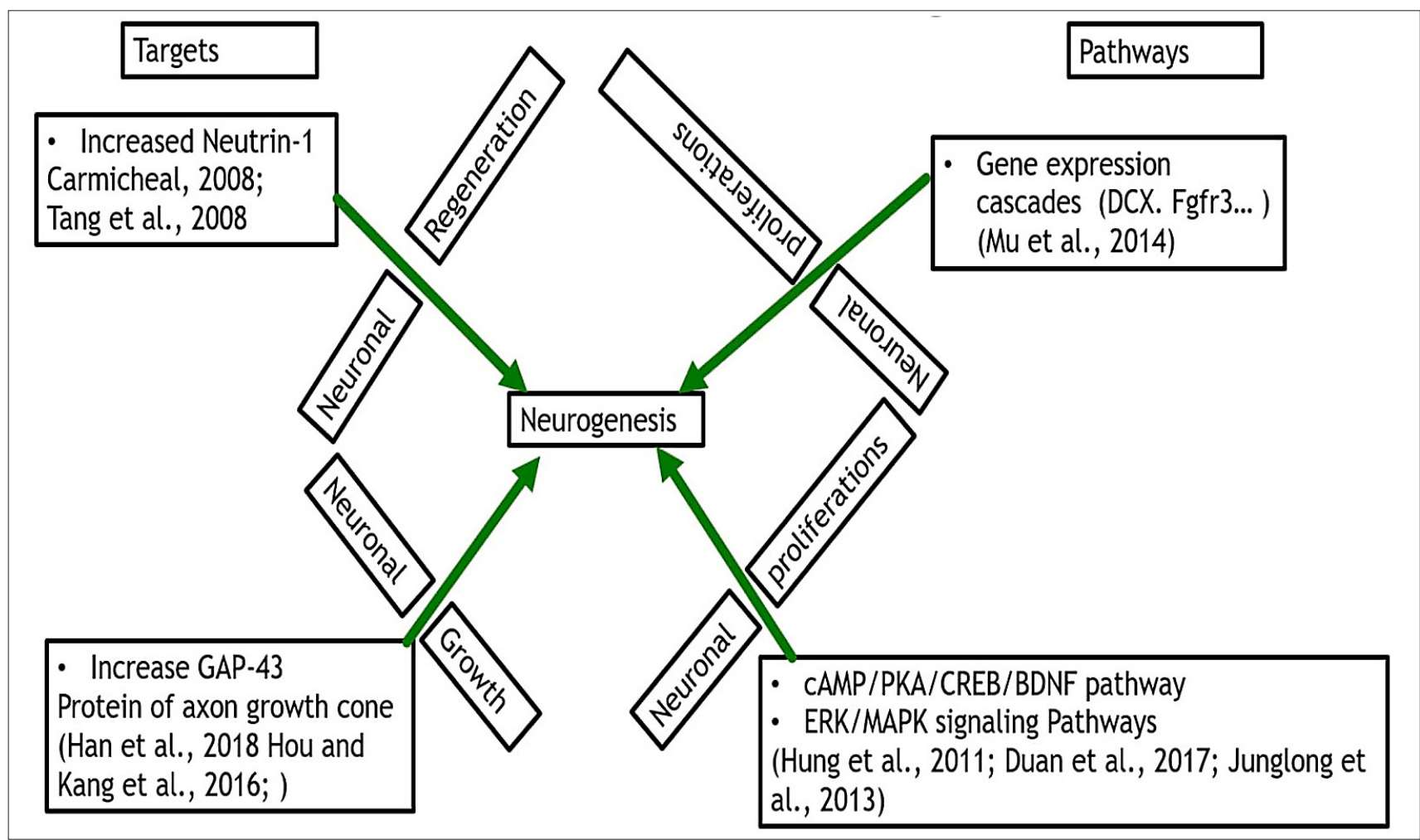

Figure 7. Molecular targets involved in the herbal medicine treatment for stroke (MTHM) via promoting neurogenesis 
43), a phosphoprotein that is common at the growth cone of axons. It is commonly associated with neuronal rewiring following brain or spinal cord injury, and therefore its increased level following treatment with $\mathrm{HM}$, such as Buyang Huanwu decoction (BHD), is an indicator of therapeuticallymediated axonal regrowth and remodelling (Fig. 7) [76, $77,78]$

Wnt/ $\beta$-catenin pathway for neural cell development. This pathway, when activated as characterized by increased expression as well as levels of wingless-related integration site (Wnt) ligand, promotes neurogenesis as well as the differentiation and survival of the newly formed neurons (Fig. 7) $[79,80]$. It can be activated by one of the HM called Huatuo Zaizao pill (HZP).

Genes for neural regeneration and development. The increased expression of DCX, Fgfr3, Cttnbp2, Rorb, Abi2 and Miat, as well as Ptprf, Ift172 and Nfib genes by the activities of HM such as Houshiheisan (HSHS), have been associated with increased neuronal regeneration and development in preclinical evaluations (Fig. 7) [81].

cAMP/PKA/CREB/Brain derived growth factor (BDNF) for neural cell development. When Brain derived growth factor (BDNF) is elevated in the neural stem cells (NSCs), they characteristically promote neuronal proliferation and differentiation [82]. The activation of BDNF gene usually follows a biological cascade of events triggered by cerebral ischemia and promoted by therapeuticall-mediated increased phosphorylation of cAMP response element-binding protein (CREB) by protein kinase A (PKA), thus generating phosphorylated-CREB ( $p$-CREB). Phosphorylated-CREB can increase transcription of the BDNF gene by binding to its cAMP response element (CRE) element of the gene promoter region (Fig. 7) $[82,83,84,85]$. HM such as HZP and BHD are very potent activatos of the cAMP/PKA/CREB/ Brain derived growth factor (BDNF) pathway.
Glial fibrillary acidic protein (GFAP) and S-100B protein for neural cell development. Attenuation of the expression of glial fibrillary acidic protein (GFAP) and $\underline{\text { S100 Calcium }}$ Binding Protein B (S-100B), which probably arises as a consequence of both an antioxidation as well as an anticoagulation related effects of herbal medication, has also been reported [72, 86, 87]. Attenuation in the level of GFAP had been associated with uninjured healthy brain tissue [81], and is therefore a biological marker for healthy neuronal tissue (Fig. 8).

Antiapoptotic / Antiinflammation. Hypoxia following stroke promotes metabolic collapse which facilitates an exaggerated rate of cell death among neurons.The normal inflammation process is chiefly concerned with the disposal of both dead cells as well as necrotic debris, while overzealous inflammation after stroke inhibits neuronal rehabilitation $[88,89]$. A number of molecular features have been highlighted in the literature that promotes antiapoptosis / anti-inflammation following cerebral ischemic injury, and include: optimization of calcium levels, attenuation of Toll-like receptor (TLR), optimization of glutamate leve, increased activity of nicotinic acetylcholine receptor $\alpha 7$ (nAChR $\alpha 7$ ) receptors, and attenuation of the activities of proinflammatory cytokines (Fig. 8).

Optimization of calcium levels. Optimization of calcium levels promote increase in the length of axons and the expression of neurofilament and GFAP $[90,91,92]$. Therapeutic strategies have also prevented intracellular calcium overload. Calcium overload is a key indicator of irreversible injury in cells. This attenuation of calcium overload also decreases the level of B-cell lymphoma $\mathbf{2}$ (Bcl-2) and caspase-dependent apoptosis (Fig. 8) [93, 94, 95, 96]. Apoptosis is generally reported as very important in the process of cell death that claims numerous neurons within the cerebral ischemia region. Therefore, $\mathrm{HM}$ such as Chuanxiongzine of $\mathrm{BHD}$ and DCH with antiapoptotic capabilities, attenuate the level

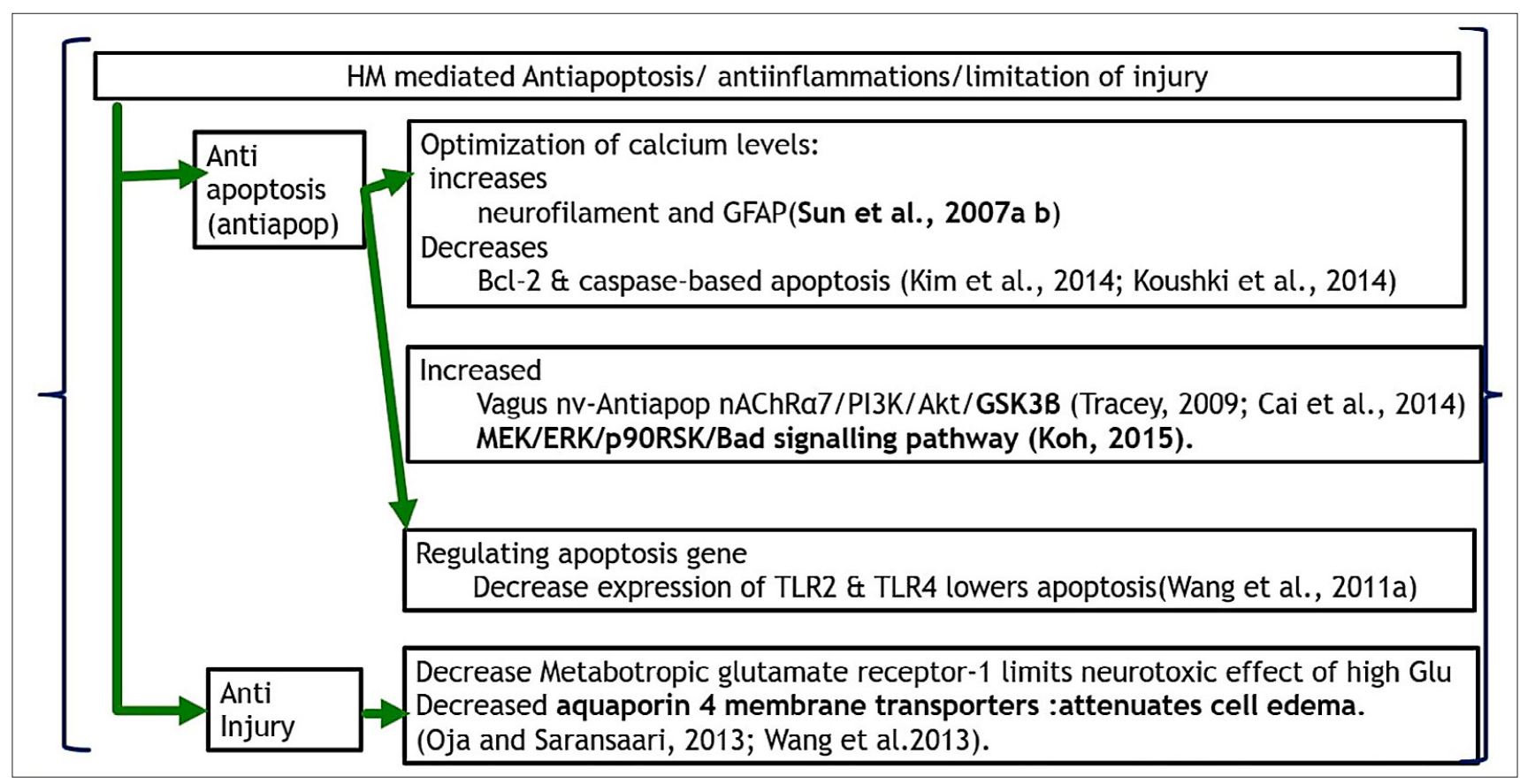

Figure 8. Molecular targets involved in the herbal medicine treatment for stroke (MTHM) via anti- inflammation and / or anti apoptosisgenesis 
of cerebral ischemic reperfusion injuries that manifests as apoptosis $[16,93,94,95,96,97,98]$.

Toll-like receptor (TLR)/myeloid differentiation factor 88 (MyD88). The level and rate of apoptosis is dependent in part on the level of expression of Toll-like receptor (TLR) / myeloid differentiation factor 88 (MyD88). Absence / attenuation of expression of specific types of TLR, such as TLR2 and TLR4, attenuates the degree to which cells malfunction and subsequently die via apoptosis after Ischemia /reperfusion injury [99]. Thus, the HM, such as Paeoniflorin, which attenuate the expression of TLR/MyD88 is a potent antiapoptotic remedy that can suppress the level of neuronal death following cerebral ischemia.

Glutamate and toxic neural effect. Glutamate, an excitatory amino acid neurotransmitter is a promoter of toxic effect on neural cells by its activity on metabotropic glutamate receptor-1 when it occurs at very high levels in the extracellular spaces $[100,101,102]$. Therefore, regulation of the level of the activity of extracellular glutamate within an optimal nontoxic limit either by downregulating its glutamate receptor-1 or other means are putatively good mechanism utilized by some herbal medicines, such as Ferulic acid (FA), in order to eliminate the neurotoxic effects of the glutamate (Fig. 8).

Aquaporin. Herbal remedies such as BYHW for treatment of cerebral ischemia reperfussion injury that attenuate the expression of aquaporin 4 with associated decreased propensity for cellular edema, have also been reported (Fig. 8) $[50]$.

Pro-inflammatory cytokines. Pro-inflammatory cytokines, such as IL-1 $\beta$ and TNF- $\alpha$, can stimulate the detrimental activity of Nuclear factor kappa B (NF-Kb) with nuclear translocation for upregulating the expression of phosphoNF- $\kappa \mathrm{B}$ p65, promoting $\mathbf{N F - \kappa B}$ inhibitory factor $\alpha$ $(\mathrm{I} \kappa \mathrm{B} \alpha)$ degradation and heightening of the expression of Protein P53 (p53) [33, 103]. These are well-known modulators of apoptosis (neuronal apoptosis) as well as structural brain injury $(33,103)$. These pro-inflammatory cytokines have also been reported to facilitate the degradation of the microenvironment around the nascent neuron with associated injuries that cumulatively shorten the life span of the neuron [104]. Herbal medicine, such as Paeoniflorin (PF), that attenuate the degradation of the microenvironment of newly-formed neurons, as well promote anti-apoptotic and anti-inflammatory effects, have great potential in the treatment of stroke (Fig. 8).

Phosphatidylinositol 3-kinase (PI3K)/ Akt/ GSK3 $\beta$ anti apoptotic pathway. The role of the the autonomic nervous system in regulating inflammation through the activity of the neural circuits on immune cells has been reported in the literature. It entails the activation of an nAChR $\alpha 7$ antiinflammatory pathway, which itself was recruited by the vagus nerve that is stimulated by circulating pro-inflammatory cytokines abintio (Fig. 8) [105, 106, 107]. Nevertheless, the increased activity of $\mathrm{nAChR} \alpha 7$ has been reported to facilitate neuronal recovery from cerebral ischemic injury). The activity of $\mathrm{nAChR} \alpha 7$ is mediated by the anti-apoptotic phosphatidylinositol 3-kinase (PI3K)/ Protein kinase B (Akt) / Glycogen synthase kinase 3 beta (GSK3 $\beta$ ) pathway, which is poles apart from the phosphatase and tensin homolog (PTEN)- ROS production pathway. The activity of the nAChR $\alpha 7$ receptor is also mediated by the proliferation-promoter $\beta$-arrestin mediated activation of Src pathways (Fig. 8) [108, $109,110,111]$. PF is the main HM that shows great promise in modulating the apoptotic effects of PI3K.

MEK/ERK/p90RSK/Bad signalling anti-apoptotic pathway. The Mitogen-activated protein kinase kinase (MEK) / extracellular signal-regulated kinases (ERK) / 90 kDa ribosomal s6 kinases (p90RSK) / Bad signalling pathway have been identified as a molecular cascade of events that prevent cerebral ischemic cell injury and death [112]. The $\mathrm{HM}$ of note that acts via this pathway is the FA.

Anti-coagulation / fibrinolysis effect. Attenuation of the aggregation of platelet, the levels of endothelin and thromboxane $\mathrm{A}_{2}$, as well as the formation of a thrombus are central factors and/or mechanisms through which herbal medication protect against, as well as promote recovery from cerebral ischemic injury (Fig. 9) [113, 114, 115]. Increased fibrinolysis within the blood through the activity of endogenous tPAr, as well as attenuation of the level of plasminogen activator inhibitor-1, have been experimentally identified as appropriate techniques used by herbal medicine, such as Huatuo Zaizao pill $(H T)$ in ameliorating the level of injury following cerebral ischemia [116].

$$
\begin{aligned}
& \text { HM increased Activity of endogenous tPAr } \\
& \text { (Kong et al., 2014; Lan et al., 2013) }
\end{aligned}
$$

HM Attenuation of plasminogen activator inhibitor-1

(Kong et al., 2014; Lan et al., 2013). 


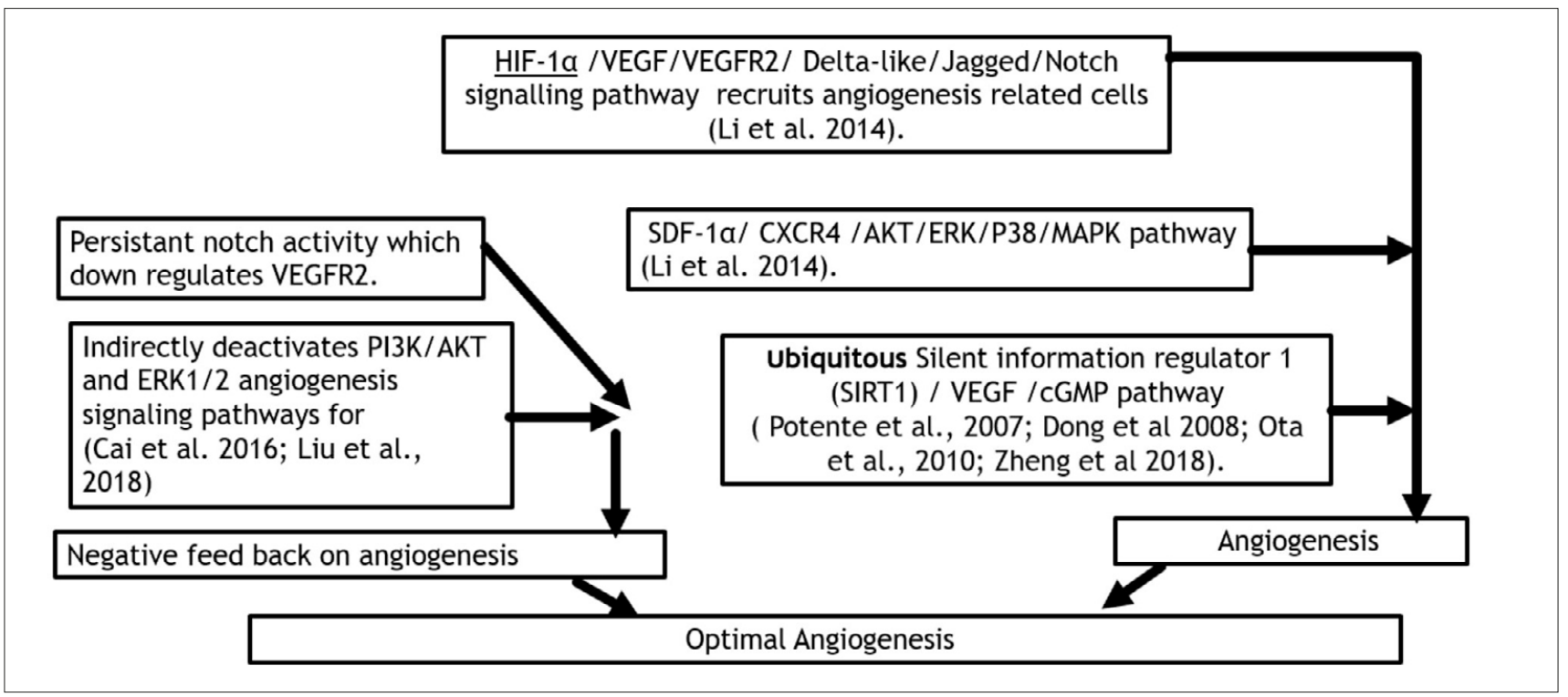

Figure 10. Molecular targets involved in the herbal medicine treatment for stroke (MTHM) via angiogenesis

Angiogenesis. There are a number of pro-angiogenesis cytokines that participate in neo-angiogenesis which include the SDF-1a a ligand for the CXCR4 receptor, as well as the VEGF ligand for VEGFR. SDF-1a recruits pro-angiogenic cells that manifest a prominent CXCR4 receptor, such as in the cells from HSCs, EPCs and smooth muscle cell progenitors, while VEGF binds to its receptor to mediate angiogenesis [117]. These two systems, SDF-1a/CXCR4 and VEGF/VEGFR2, for recruiting angiogenesis related cells are reportedly parallel [117]. Rodent models of cerebral ischemia have been shown to have an up-regulation of SDF$1 \alpha / C X C R 4$ axis with associated activation of AKT, ERK, and P38 mitogen-activated protein kinase (MAPK) signalling pathways in the ischemic region of the brain, as well as increased angiogenesis and neurogenesis [118]. Increased activity of HIF-1a, which primarily promotes activity of the VEGF / Delta-like/Jagged/Notch signalling pathway for angiogenesis, have been reported following treatment of stroke with herbal medicine (Fig. 10) [118]. Improvement in the activation of protein kinase $\mathrm{B}(\mathrm{AKT}) / \mathrm{mammalian}$ target of rapamycin (mTOR)/ hypoxia-inducible factor-1 alpha (HIF-1a) pathway, as well as ERK1/2 molecular cascade, has also been documented in the literature and associated with the production of VEGF [117]. The outcomes, following the activation of these pathways include increase vascular density in in vivo studies, as well as increased BMEC migration and tube formation in in vitro studies [117].

The binding of VEGF on VEGFR activates tyrosine kinases with a number of downstream activities that promote angiogenesis $[47,117,119,120]$. The VEGF cascades also promote the production of Delta-like 4 (Dll4) which is a specific endothelial ligand for Notch1 receptor in the arteries, and this component of the Notch signalling specifically promotes lumen morphogenesis in the next $1 \mathrm{~h}$ suppression of the migration and proliferation of endothelial progenitor cells (EC) by down-regulating VEGFR, as well as indirect deactivation of the PI3K/AKT and ERK1/2 signalling pathways, also associated with the decline in the Notch signaling [121, 122]. This feedback activity helps militate against the detrimental effect of unchecked angiogenesis such as vascular malformations and hemorrhage $[117,123]$.
The key HM involved in optimizing angiogenesis include Angelica gigas NAKAI (AG) and FA.

The ubiquitous nature of silent information regulator $1 /$ sirtuin 1 (SIRT1) implicates it in many cells for a number of processes, such as inflammation, oxidation-stress, apoptosis, myogenesis and energy metabolism, due to its ability to interact with a wide range of transcription factors $[124,125$, 126]. Increased activity of the SIRT1/ Vascular endothelial growth factor (VEGF) / Cyclic Guanosine Mono Phosphate) (cGMP) pathway is a key pathway that plays a vital role in promoting angiogenesis, as reported in preclinical experimental studies with some HM such as BHD (Fig. 10) $[16,127,128,129]$. Experimental evidence suggests that the level of VEGF begins to rise hours after cerebral reperfusion following an ischemic episode, and the rise in VEGF level plays a significant role in preventing cerebral damage during the delayed phase [128].

The activity of VEGF commonly occurs in tandem with the activity of Ang-1 which is essential for maturation and stabilization of blood vessels under either physiologic or pathologic conditions $[130,131,132,133,13,135]$. It is also one of the ligands for tyrosine receptors (Tie-2) and the activation of this receptor leads to down-regulation of inflammatory responses associated with angiogenesis. It also promotes the expression of intracellular adhesion molecules, such as ICAM-1, Vascular cell adhesion protein 1 (VCAM-1) and endothelial-leukocyte adhesion molecule 1 (E-selectin) in endothelial cells during brain inflammation [23]. Generally, increased expression of vascular endothelial growth factor (VEGF), Ang-1, as well as late onset of increase in F1K1 expression had been reported in stroke studies that examined these angiogenesis-related proteins (ARP) protein (Fig. 9) [19, 136]. Herbal medicines such as Angelica gigas NAKAI (AG) and FA that modulate the expression and activities of ARP have shown promising results in the preclinical treatment of stroke.

Metabolism. A putative mechanism of action involving multitarget herbal medicinal products relies on the modulation of metabolism in the neuronal / glial cell pair following cerebral injury. Increased $\underline{\mathrm{N} \text {-Acetylaspartate (NAA) / Creatine (Cr) }}$ 


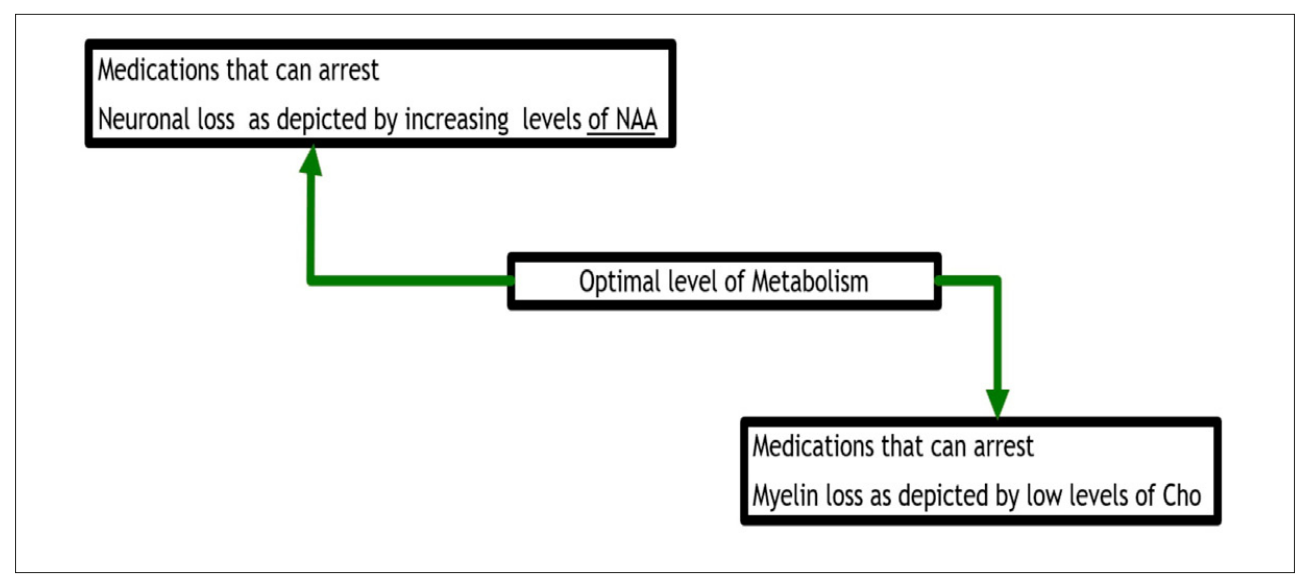

Figure 11. Molecular targets involved in the herbal medicine treatment for stroke (MTHM) via optimization of metabolizm

ratio, as well as decreased Choline (Cho) / creatine (Cr) ratios were common in the initial time points after stroke among models receiving herbal medicine treatment [137] (Fig. 11). NAA metabolites depict the level of viability of neuron, while the Cho metabolite is mainly composed of compounds found in the cell membrane and depicts the level of metabolism (myelinization, proliferation and membrane function) in the supporting glial cells [137]. Attenuation of the levels of NAA suggests a high level of neuronal loss, while an elevated level of Cho is highly suggestive of dissolution of myelin as well as astrocytic gliosis [137, 138, 139, 140]. Therefore, HM such as Xiaoshuan enteric-coated capsule and BYHWD which are geared towards optimization of metabolic capabilities of neurons, have a strong promise for attenuating the detrimental effect of cerebral ischemia injuries (Fig. 11).

\section{CONCLUSIONS}

There is a dearth of clinically approved medications for the management of stroke, and those available are successful only in a few patients. The current review had successfully highlighted the efficacy of the HM, such as BHD, FA and HZP, and in ameliorating post-ischemic pathophysiology, which is an addition to the widely-held belief among researchers that they are best suited for preventive application. In addition, the multi-target molecular action of HM identified in this review may present clues for the development of more stroke medications based on its diverse approaches in ameliorating the pathophysiology of stroke. Therefore, the current review promotes awareness of the potential supportive role for HM which adds to the established available definitive treatment options for stroke, as well as providing a molecular compendium for potential druggable targets for stroke treatment.

\section{REFERENCES}

1. Del Zoppo GJ. The neurovascular unit in the setting of stroke. J Intern Med. 2010; 267(2): 156-71. doi: 10.1111/j.1365-2796.2009.02199.x

2. Woodruff TM, Thundyil J, Tang SC, Sobey CG, Taylor SM, Arumugam TV. Pathophysiology, treatment, and animal and cellular models of human ischemic stroke. Mol Neurodegener. 2011; 6(1): 1-19. doi: 10.1186/1750-1326-6-11

3.Xiong Y, Mahmood A, Chopp M. Angiogenesis, neurogenesis and brain recovery of function following injury. Curr Opin Investig Drugs. 2010; 11(3): 298-308.
4. Tian C, Cao X, Wang J. Recanalisation therapy in patients with acute ischaemic stroke caused by large artery occlusion: Choice of therapeutic strategy according to underlying aetiological mechanism? Stroke Vasc Neurol. 2017; 2(4): 244-50. doi: 10.1136/svn-2017-000090

5. Haghjoo R, Tadjalli M. Effect of Persian Sage (Salvia rhytidia) Extract on Histomorphometric Changes of Cerebral Cortex and Hippocampus Following Ischemia-Reperfusion Injuries in Rat. Zahedan J Res Med Sci. 2016; 18(2): e5993. doi: 10.17795/zjrms-5993

6. McColl BW, Rothwell NJ, Allan SM. Systemic inflammatory stimulus potentiates the acute phase and CXC chemokine responses to experimental stroke and exacerbates brain damage via interleukin-1and neutrophil-dependent mechanisms. J Neurosci. 2007; 27: 4403-12. doi: 10.1523/JNEUROSCI.5376-06.2007

7.Zhou Z, Wei X, Xiang J, Gao J, Wang L, You J, et al. Protection of erythropoietin against ischemic neurovascular unit injuries through the effects of connexin43. Biochem Biophys Res Commun. 2015; 458: 656-62. doi: 10.1016/j.bbrc.2015.02.020

8. Pan J, Lei X, Wang J, Huang S, Wang Y, Zhang Y, et al. Effects of Kaixinjieyu, a Chinese herbal medicine preparation, on neurovascular unit dysfunction in rats with vascular depression. BMC Complement Altern Med. 2015; 15: 291. doi: 10.1186/s12906-015-0808-Z

9. Vangilder RL, Rosen CL, Barr TL, Huber JD. Targeting the neurovascular unit for treatment of neurological disorders. Pharmacol Ther. 2011; 130: 239-47. doi: 10.1016/j.pharmthera.2010.12.004

10. Niu T, Qin ZS, Xu X, Liu JS. Bayesian Haplotype Inference for Multiple Linked Single-Nucleotide Polymorphisms. Am J Hum Genet. 2002; 70: 157-169. doi: 10.1086/338446

11. Powers WJ, Rabinstein AA, Ackerson T, Adeoye OM, Bambakidis NC, Becker K, et al. 2018 Guidelines for the Early Management of Patients With Acute Ischemic Stroke: A Guideline for Healthcare Professionals From the American Heart Association/American Stroke Association. Stroke. 2018; 49: e46-e110. doi: 10.1161/STR.0000000000000158

12.Zhang X, Zheng W, Wang T, Ren P, Wang F, Ma X, et al. DanshenChuanxiong-Honghua ameliorates cerebral impairment and improves spatial cognitive deficits after transient focal ischemia and identification of active compounds. Front Pharmacol. 2017; 8: 452. doi: 10.3389/fphar.2017.00452

13. Montaner J, Molina CA, Monasterio J, Abilleira S, Arenillas JF, Ribó $\mathrm{M}$, et al. Matrix metalloproteinase- 9 pretreatment level predicts intracranial hemorrhagic complications after thrombolysis in human stroke. Circulation. 2003; 107: 598-603. doi: 10.1161/01. CIR.0000046451.38849.90

14. Warach S, Latour LL. Evidence of reperfusion injury, exacerbated by thrombolytic therapy, in human focal brain ischemia using a novel imaging marker of early blood-brain barrier disruption. Stroke. 2004; 35: 2659-61. doi: 10.1161/01.STR.0000144051.32131.09

15. Wang Y, Fan X, Qu H, Gao X, Cheng Y. Strategies and Techniques for Multi-Component Drug Design from Medicinal Herbs and Traditional Chinese Medicine. Curr Top Med Chem. 2012; 12: 1356-1362. doi: $10.2174 / 156802612801319034$

16.Zheng X-W, Shan C-S, Xu Q-Q, Wang Y, Shi Y-H, Wang Y, et al. Buyang Huanwu Decoction Targets SIRT1/VEGF Pathway to Promote Angiogenesis After Cerebral Ischemia/Reperfusion Injury. Front Neurosci. 2018; 12: 911. doi: 10.3389/fnins.2018.00911

17. Darioush S. O, Reza. R, Mazyar H, Homayoun S-B, Mohsen S-B, Elyar S-H, Sina Z, Ehsan S. The effect of Ginkgo biloba on functional 
outcome of patients with acute ischemic stroke: A double-blind placebo-controlled, randomized clinical trial. J Stroke Cerebrovasc Dis. 2013; 22: e557-563. doi: 10.1016/j.jstrokecerebrovasdis.2013.06.010

18.Xia W, Lu YJ, Yuan DC, Kong DZ, Qi WC KF. Efficacy of Huatuo Zaizao Pills for ischemic stroke. Eval Anal Drug Hosp China. 2012; 12: 772-5. doi: 10.1177/0265407510389126

19. Cai YF, Xu Y, Guo JW, Zhang XC, Li WF, Liang WX HY. The metaanalysis about the clinical efficacy of Huatuo Zaizao pills on ischemic stroke. Chin Tradit Herb Drug. 2007; 4: 581-4. doi: 10.1111/j.15374726.2004.133_10.x

20. Castro P, Azevedo E, Serrador J, Rocha I, Sorond F. Hemorrhagic transformation and cerebral edema in acute ischemic stroke: Link to cerebral autoregulation. J Neurol Sci. 2017; 372: 256-61. doi: 10.1016/j. jns.2016.11.065

21. Jiang M, Li J, Peng Q, Liu Y, Liu W, Luo C, et al. Neuroprotective effects of bilobalide on cerebral ischemia and reperfusion injury are associated with inhibition of pro-inflammatory mediator production and downregulation of JNK1/2 and p38 MAPK activation. J Neuroinflammation. 2014; 11(1): 167. doi: 10.1186/s12974-014-0167-6

22. Pillai DR, Dittmar MS, Baldaranov D, Heidemann RM, Henning EC, Schuierer G, et al. Cerebral ischemia-reperfusion injury in rats - A 3 T MRI study on biphasic blood-brain barrier opening and the dynamics of edema formation. J Cereb Blood Flow Metab. 2009; 29(11): 1846-55. doi: $10.1038 /$ jcbfm.2009.106

23. Oh TW, Park KH, Jung HW, Park YK. Neuroprotective effect of the hairy root extract of Angelica gigas NAKAI on transient focal cerebral ischemia in rats through tOh, T. W, Park KH, Jung HW, Park YK. Neuroprotective effect of the hairy root extract of Angelica gigas NA. BMC Complement Altern Med. 2015; 15: 101. doi: 10.1186/ s12906-015-0589-4

24. Sawada N, Murata M, Kikuchi K, Osanai M, Tobioka H, Kojima T, et al. Tight junctions and human diseases. Med Electron Microsc. 2003; 36: 147-56. doi: 10.1007/s00795-003-0219-y

25. Stevenson BR. Understanding tight junction clinical physiology at the molecular level. J Clin Invest. 1999; 104: 3-4. doi: 10.1172/JCI7599

26. Furuse M, Itoh M, Hirase T, Nagaftichi A, Yonemura S, Tsukita S, et al. Direct association of occludin with ZO-1 and its possible involvement in the localization of occludin at tight junctions. J Cell Biol. 1994; 127: 1617-26. doi: 10.1083/jcb.127.6.1617

27. Bardutzky J, Schwab S. Antiedema therapy in ischemic stroke. Stroke. 2007; 38(11): 3084-94. doi: 10.1161/STROKEAHA.107.490193

28. Lo EH, Dalkara T, Moskowitz MA. Mechanisms, challenges and opportunities in stroke. Nat Rev Neurosci. 2003; 4: 399-415. doi: $10.1038 / \mathrm{nrn} 1106$

29. Thurston G, Suri C, Smith K, McClain J, Sato TN, Yancopoulos $\mathrm{GD}$, et al. Leakage-resistant blood vessels in mice transgenically overexpressing angiopoietin-1. Science (80-). 1999; 286(5449): 2511-4. doi: $10.1126 /$ science.286.5449.2511

30. Barrington J, Lemarchand E, Allan SM. A brain in flame; do inflammasomes and pyroptosis influence stroke pathology? Brain Pathol. 2017; 27: 205-212. doi: 10.1111/bpa.12476

31. Ramsauer M, Krause D, Dermietzel R. Angiogenesis of the blood-brain barrier in vitro and the function of cerebral pericytes. FASEB J. 2002; 16: 1274-6. doi: 10.1096/fj.01-0814fje

32. Fruttiger M, Calver AR, Krüger WH, Mudhar HS, Michalovich D, Takakura N, et al. PDGF mediates a neuron-astrocyte interaction in the developing retina. Neuron. 1996; 17: 1117-31. doi: 10.1016/S08966273(00)80244-5

33. Shan H, Bian Y, Shu Z, Zhang L, Zhu J, Ding J, et al. Fluoxetine protects against IL-1 $\beta$-induced neuronal apoptosis via downregulation of p53. Neuropharmacology. 2016; 107: 68-78. doi: 10.1016/j. neuropharm.2016.03.019

34. Nicotera P, Bano D. The Enemy at the Gates: Ca2+ Entry through TRPM7 Channels and Anoxic Neuronal Death. Cell. 2003; 115(7): 768-70. doi: 10.1016/S0092-8674(03)01019-5

35. Yeh TH, Hwang HM, Chen JJ, Wu T, Li AH, Wang HL. Glutamate transporter function of rat hippocampal astrocytes is impaired following the global ischemia. Neurobiol Dis. 2005; 18(3): 476-83. doi: $10.1016 /$ j.nbd.2004.12.011

36. Rao VLR, Dogan A, Bowen KK, Todd KG, Dempsey RJ. Antisense knockdown of the glial glutamate transporter GLT-1 exacerbates hippocampal neuronal damage following traumatic injury to rat brain. Eur J Neurosci. 2001; 13(1): 119-28. doi: 10.1046/j.1460-9568.2001.01367.x

37. Bruhn T, Levy LM, Nielsen M, Christensen T, Johansen FF, Diemer $\mathrm{NH}$. Ischemia induced changes in expression of the astrocyte glutamate transporter GLT1 in hippocampus of the rat. Neurochem Int. 2000; 37(2-3): 277-85. doi: 10.1016/S0197-0186(00)00029-2
38.Xuan Chi X, Xu ZC. Potassium currents in CA1 neurons of rat hippocampus increase shortly after transient cerebral ischemia. Neurosci Lett. 2000; 281(1): 5-8. doi: 10.1016/S0304-3940(00)00812-0 39. Decollogne S, Bertrand IB, Ascensio M, Drubaix I, Lelievre LG. Na+, $\mathrm{K}+-\mathrm{ATPase}$ and $\mathrm{Na}+\mathrm{Ca} 2+$ exchange isoforms: Physiological and physiopathological relevance. J Cardiovasc Pharmacol. 1993; 22: S96-8.

40. Simard JM, Tarasov K V, Gerzanich V. Non-selective cation channels, transient receptor potential channels and ischemic stroke. Biochim Biophys Acta - Mol Basis Dis. 2007; 1772: 947-57. doi: 10.1016/j. bbadis.2007.03.004

41. Salińska E, Lazarewicz JW. NMDA receptor-mediated calcium fluxes in the hippocampus: relevance to ischemic brain pathology. Neurol Neurochir Pol. 1996; 30: 35-42.

42.Xiong ZG, Chu XP, Simon RP. Ca2+-permeable acid-sensing ion channels and ischemic brain injury. J Membr Biol. 2006; 209: 59-68. doi: 10.1007/s00232-005-0840-X

43. Evans $\mathrm{PH}$, Free radicals in brain metabolism and pathology. Br Med Bull. 1993; 49(3): 577-87. doi: 10.1210/er.2006-0040

44. Khooei AR, Hosseinzade H IM. Pathologic evaluation of anti-ischemic effect of Salvia leriifolia Benth seed and leaf extracts in rats after global cerebral ischemia. Iran J Basic Med Sci. 2003; 5(4): 8-13. doi: 10.4103/1735-5362.213985 LK

45. Hosseinzadeh H, Hosseini A, Nassiri-Asl M, Sadeghnia HR. Effect of Salvia leriifolia Benth. root extracts on ischemia-reperfusion in rat skeletal muscle. BMC Complement Altern Med. 2007; 7: 23. doi: 10.1186/1472-6882-7-23

46. Ke Q, Costa, M. Hypoxia-inducible factor-1 (HIF-1). Mol. Pharmacol. 2006; 70(5): 1469-1480.

47. Chen Y, Han L, Li J, Chen Y, Zhang M, Qian L, et al. Human urinary kallidinogenase promotes angiogenesis and cerebral perfusion in experimental stroke. PLoS One. 2015; 10(7): e0134543. doi: 10.1371/ journal.pone.0134543

48. Rosenblum WI. Cytotoxic edema: Monitoring its magnitude and contribution to brain swelling. J Neuropathol Exp Neurol. 2007; 66(9): 771-778. doi.org/10.1097/nen.0b013e3181461965

49. Giraldez T, Dominguez J, de la Rosa DA. ENaC in the Brain - Future Perspectives and Pharmacological Implications. Curr Mol Pharmacol. 2016; 6(1): 44-49. doi: 10.2174/1874467211306010006

50.Zhou Y, Li HQ, Lu L, Fu DL, Liu AJ, Li JH, et al. Ginsenoside Rg1 provides neuroprotection against blood brain barrier disruption and neurological injury in a rat model of cerebral ischemia/reperfusion through downregulation of aquaporin 4 expression. Phytomedicine. 2014; 21(7): 998-1003. doi.org/10.1016/j.phymed.2013.12.005

51. Ruan L, Wang B, Zhuge Q, Jin K. Coupling of neurogenesis and angiogenesis after ischemic stroke. Brain Res. 2015; 1623: 166-173. doi: 10.1016/j.brainres.2015.02.042

52. Valable S, Montaner J, Bellail A, Berezowski V, Brillault J, Cecchelli R. et al. VEGF-induced BBB permeability is associated with an MMP-9 activity increase in cerebral ischemia: Both effects decreased by Ang1. J Cereb Blood Flow Metab. 2005; 25(11): 1491-1504. doi: 10.1038/ sj.jcbfm. 9600148

53. Chen ZZ, Gong X, Guo Q, Zhao H, Wang L. Bu Yang Huan Wu decoction prevents reperfusion injury following ischemic stroke in rats via inhibition of HIF-1 $\alpha$ VEGF and promotion $\beta$-ENaC expression. J Ethnopharmacol. 2019; 10(228): 70-81. doi: 10.1016/j.jep.2018.09.017

54. Baranova O, Miranda LF, Pichiule P, Dragatsis I, Johnson RS, Chavez JC. Neuron-specific inactivation of the hypoxia inducible factor $1 \alpha$ increases brain injury in a mouse model of transient focal cerebral ischemia. J Neurosci. 2007; 27(23): 6320-6332. doi: 10.1523/ JNEUROSCI.0449-07.2007

55. Yeh WL, Lu DY, Lin CJ, Liou HC, Fu WM. Inhibition of hypoxia-induced increase of blood-brain barrier permeability by YC-1 through the antagonism of HIF-1 $\alpha$ accumulation and VEGF expression. Molecular Pharmacol. 2007; 72(2): 440-449. doi: 10.1124/mol.107.036418

56. Lee JH, Cui HS, Shin SK, Kim JM, Kim SY, Lee JE, et al. Effect of propofol post-treatment on blood-brain barrier integrity and cerebral edema after transient cerebral ischemia in rats. Neurochem Res. 2013; 38(11): 2276-2286. doi: 10.1007/s11064-013-1136-7

57. Nada SE, Shah ZA. Preconditioning with Ginkgo biloba (EGb 761 ${ }^{\oplus}$ ) provides neuroprotection through HO1 and CRMP2. Neurobiol Dis. 2012; 46: 180-189. doi.org/10.1016/j.nbd.2012.01.006

58. Nada SE, Tulsulkar J, Shah, ZA. Heme oxygenase 1-mediated neurogenesis is enhanced by Ginkgo biloba (EGb 761 ${ }^{\oplus}$ ) after permanent ischemic stroke in mice. Molecular Neurobiol. 2014; 49: 945-956. doi: 10.1007/s12035-013-8572-x

59. Shah ZA, Nada SE, Doré S. Heme oxygenase 1, beneficial role in permanent ischemic stroke and in Gingko biloba (EGb 761) 
neuroprotection. Neurosci. 2011; 180: 248-255. doi: 10.1016/j. neuroscience.2011.02.031

60. Cisowki J, Loboda A, Jozkowicz A, Chen S, Agarwai A, Dulak J. Role of heme oxygenase-1 in hydrogen peroxide-induced VEGF synthesis: Effect of HO-1 knockout. Biochem Biophys Res Commun. 2005; 326: 670-676. doi: 10.1016/j.bbrc.2004.11.083

61.Lin HH, Lai SC, Chau LY. Heme oxygenase-1/carbon monoxide induces vascular endothelial growth factor expression via $\mathrm{p} 38$ kinasedependent activation of Sp1. J Biol Chem. 2011; 286: 3829-3838. oi.org/10.1074/jbc.M110.168831

62. Crews L, Ruf R, Patrick C, Dumaop W, Trejo-Morales M, Achim $\mathrm{CL}$, et al. Phosphorylation of collapsin response mediator protein-2 disrupts neuronal maturation in a model of adult neurogenesis: Implications for neurodegenerative disorders. Mol Neurodegener. 2011; 6: 67. doi.org/10.1186/1750-1326-6-67

63. Higurashi M, Iketani M, Takei K, Yamashita N, Aoki R, Kawahara $\mathrm{N}$, Goshima Y. Localized role of CRMP1 and CRMP2 in neurite outgrowth and growth cone steering. Dev Neurobiol. 2012; 72: 1528 1540. doi.org/10.1002/dneu.22017

64. Ren Z, Li Y, Zhang R, Li Y, Yang Z, Yang H. Ferulic acid exerts neuroprotective effects against cerebral ischemia/reperfusion-induced injury via antioxidant and anti-apoptotic mechanisms in vitro and in vivo. Int J Mol Med. 2017; 40(5): 1444-1456(13). doi: 10.3892/ijmm.2017.3127

65. Kim JJ, Khan WI. 5-HT7 receptor signaling: improved therapeutic strategy in gut disorders. Front Behav Neurosci. 2014; 8: 396. doi. org/10.3389/fnbeh.2014.00396

66. Arvidsson A, Collin T, Kirk D, Kokaia Z, Olle L. Neuronal replacement from endogenous precursors in the adult. Nat Med. 2003; 8: 963-970. doi: $10.1038 / \mathrm{nm} 747$

67. Rueger M, Backes H, Walberer M, Neumaier B, Ullrich R, Emig B, et al. Non-invasive imaging of endogenous neural stem cell mobilization in vivo using Positron Emission Tomography. Klinische Neurophysiol. 2012; 7: 75-83. doi: 10.1523/JNEUROSCI.6092-09.2010

68. Carmichael ST. Themes and strategies for studying the biology of stroke recovery in the poststroke epoch. Stroke. 2008; 39: 1380-1388. doi: 10.1161/STROKEAHA.107.499962

69. Tang X, Jang SW, Okada M, Chan CB, Feng Y, Liu Y, et al. Netrin-1 mediates neuronal survival through PIKE-L interaction with the dependence receptor UNC5B. Nat Cell Biol. 2008; 10: 698-706. doi: $10.1038 /$ ncb1732

70. Nishimoto S, Nishida E. MAPK signalling: ERK5 versus ERK1/2. EMBO Rep. 2006; 7: 782-786. doi: 10.1038/sj.embor.7400755

71. Berwick DC, Calissano M, Corness JD, Cook SJ, Latchman DS. Regulation Of Brn-3a N-terminal transcriptional activity by MEK1/2ERK1/2 signalling in neural differentiation. Brain Res. 2009; 1256: 8-18. doi: 10.1016/j.brainres.2008.12.009

72. Huang CY, Chang YM, Kuo WH, Lai TY, Shih YT, Tsai FJ, et al. RSC96 schwann cell proliferation and survival induced by dilong through PI3K/Akt signaling mediated by IGF-I. Evidence-based Complement Altern Med. 2011; 216148. doi: 10.1093/ecam/nep216

73. Duan Z, Zhang X, Zhu GX, Gao Y, Xue X. Activation of mGluR4 promotes proliferation of rat neural progenitor cells while mediating activation of ERK1/2 signaling pathway. Cell Mol Biol (Noisy-legrand). 2013; 59(suppl): OL1809-1817.

74. Ishii A, Furusho M, Bansal R. Sustained activation of ERK1/2 MAPK in oligodendrocytes and schwann cells enhances myelin growth and stimulates oligodendrocyte progenitor expansion. J Neurosci. 2013; 33: 175-186. doi:10.1523/JNEUROSCI.4403-12.2013.

75. Jinglong T, Weijuan G, Jun L, Tao Q, Hongbo Z, Shasha L. The molecular and electrophysiological mechanism of Buyanghuanwu Decoction in learning and memory ability of vascular dementia rats. Brain Res Bull. 2013; 99: 13-8. doi: 10.1016/j.brainresbull.2013.09.002

76. Han J, Zhang JZ, Zhong ZF, Li ZF, Pang WS, Hu J, et al. Gualou Guizhi decoction promotes neurological functional recovery and neurogenesis following focal cerebral ischemia/reperfusion. Neural Regen Res. 2018; 13(8): 1408-1416. doi: 10.4103/1673-5374.235296

77. Stokowska A, Atkins AL, Morán J, Pekny T, Bulmer L, Pascoe MC, et al. Complement peptide C3a stimulates neural plasticity after experimental brain ischaemia. Brain. 2017; 140: 353-369. doi: 10.1093/ brain/aww314

78. Hou Y jin, Kang H peng. Effects of acupuncture and rehabilitation therapy on the expression of growth associated protein-43 and synaptophysin at the injury site of cerebral palsy rats. Chinese J Tissue Eng Res. 2016; 20: 3999-4005. doi: 10.3969/j.issn.2095-4344.2016.27.007

79. Shruster A, Ben-Zur T, Melamed E, Offen D. Wnt signaling enhances neurogenesis and improves neurological function after focal ischemic injury. PLoS One. 2012; 7: e40843. doi: 10.1371/journal.pone.0040843
80. Raghavan A, Shah ZA. Repair and regeneration properties of Ginkgo biloba after ischemic brain injury. Neural Regen Res. 2014; 9(1): 11041107. doi: 10.4103/1673-5374.135308

81. Mu Q, Liu P, Hu X, Gao H, Zheng X, Huang H. Neuroprotective effects of buyang huanwu decoction on cerebral ischemia-induced neuronal damage. Neural Regen Res. 2014; 9(17): 1621-1627. doi: 10.4103/1673-5374.141791

82. Duan S, Wang T, Zhang J, Li M, Lu C, Wang L, et al. Huatuo Zaizao pill promotes functional recovery and neurogenesis after cerebral ischemia-reperfusion in rats. BMC Complement Altern Med. 2017; 17: 19. doi: 10.1186/s12906-016-1516-z

83. Yamamoto KK, Gonzalez GA, Biggs WH, Montminy MR. Phosphorylation-induced binding and transcriptional efficacy of nuclear factor CREB. Nature. 1988; 334(6182): 494-8. doi: $10.1038 / 334494 \mathrm{a} 0$

84. Nehlig A. The neuroprotective effects of cocoa flavanol and its influence on cognitive performance. Br J Clin Pharmacol. 2013; 75(3): 716-27. doi: 10.1111/j.1365-2125.2012.04378.x

85. Iguchi H, Mitsui T, Ishida M, Kanba S, Arita J. cAMP response elementbinding protein (CREB) is required for epidermal growth factor (EGF)induced cell proliferation and serum response element activation in neural stem cells isolated from the forebrain subventricular zone of adult mice. Endocr J. 2011; 58(9): 747-59. doi: 10.1507/endocrj.K11E-104

86. Wei S, Yin X, Kou Y, Jiang, B. (2009). Lumbricus extract promotes the regeneration of injured peripheral nerve in rats. J Ethnopharmacol. 2009; 123: 51-54. doi.org/10.1016/j.jep.2009.02.030

87. Ren Y, Houghton P, Hider RC. Relevant activities of extracts and constituents of animals used in traditional Chinese medicine for central nervous system effects associated with Alzheimer's disease. J Pharm Pharmacol. 2006; 58(7): 989-96. doi: 10.1211/jpp.58.7.0015

88. Zaleska MM, Mercado MLT, Chavez J, Feuerstein GZ, Pangalos MN, Wood A. The development of stroke therapeutics: Promising mechanisms and translational challenges. Neuropharmacol. 2009; 56: 329-341. doi: 10.1016/j.neuropharm.2008.10.006

89. Neumann S, Shields NJ, Balle T, Chebib M CA. Innate Immunity and Inflammation Post-Stroke: An alpha7-Nicotinic Agonist Perspective. Int J Mol Sci. 2016; 16: 29029-29046. doi: 10.1111/joa.12473

90. Catterall WA. Structure and Regulation of Voltage-Gated Ca 2+ Channels. Annu Rev Cell Dev Biol. 2000; 16: 521-555. doi: 10.1146/ annurev.cellbio.16.1.521

91. Sun K, Wang CS, Guo J, Horie Y, Fang SP, Wang F, et al. Protective effects of ginsenoside Rb1, ginsenoside Rg1, and notoginsenoside R1 on lipopolysaccharide-induced microcirculatory disturbance in rat mesentery. Life Sci. 2007; 81: 509-518. doi: 10.1016/j.lfs.2007.06.008

92. Sun J, Bi Y, Guo L, Qi X, Zhang J, Li G, et al. Buyang Huanwu Decoction promotes growth and differentiation of neural progenitor cells: Using a serum pharmacological method. J Ethnopharmacol. 2007; 113: 199203. doi: $10.1016 /$ j.jep.2007.05.018

93. Wu PF, Zhang Z, Wang F, Chen JG. Natural compounds from traditional medicinal herbs in the treatment of cerebral ischemia/ reperfusion injury. Acta Pharmacol Sin. 2010; 31: 1523-31. doi: 10.1038/ aps.2010.186

94. Gong G, Xiang L, Yuan L, Hu L, Wu W, Cai L, et al. Protective effect of glycyrrhizin, a direct HMGB1 inhibitor, on focal cerebral ischemia/ reperfusion-induced inflammation, oxidative stress, and apoptosis in rats. PLoS One. 2014; 9: e89450. doi: 10.1371/journal.pone.0089450

95. Kim DH, Lee HE, Kwon KJ, Park SJ, Heo H, Lee Y, et al. Early immature neuronal death initiates cerebral ischemia-induced neurogenesis in the dentate gyrus. Neuroscience. 2015; 284C: 42-54. doi: 10.1016/j. neuroscience.2014.09.074

96. Koushki D, Latifi S, Javidan AN, Matin M. Efficacy of some nonconventional herbal medications (sulforaphane, tanshinone iia, and tetramethylpyrazine) in inducing neuroprotection in comparison with interleukin-10 after spinal cord injury: A meta-analysis. J Spinal Cord Med. 2015; 38(1): 13-22. doi: 10.1179/2045772314Y.0000000215

97. Zhang M, Gao F, Teng F, Zhang C. Tetramethylpyrazine promotes the proliferation and migration of brain endothelial cells. Mol Med Rep. 2014; 10: 29-32. doi:10.3892/mmr.2014.2169

98.Zhang Q, Zhao YH. Therapeutic angiogenesis after ischemic stroke: Chinese medicines, bone marrow stromal cells (bmscs) and their combinational treatment. Am J Chin Med. 2014; 42(01): 61-77. doi: 10.1142/S0192415X14500049

99. Wang HW, Liou KT, Wang YH, Lu CK, Lin YL, Lee IJ, et al. Deciphering the neuroprotective mechanisms of Bu-yang Huan-wu decoction by an integrative neurofunctional and genomic approach in ischemic stroke mice. J Ethnopharmacol. 2011; 138: 22-33. doi: 10.1016/j. jep.2011.06.033 
100. Oja SS, Saransaari P. Ischemia Induces Release of Endogenous Amino Acids from the Cerebral Cortex and Cerebellum of Developing and Adult Mice. J Amino Acids. 2013; 2013(839036). doi: 10.1155/2013/839036

101. Wang L, Huang Y, Wu J, Lv G, Zhou L, Jia J. Effect of Buyang Huanwu decoction on amino acid content in cerebrospinal fluid of rats during ischemic/reperfusion injury. J Pharm Biomed Anal. 2013; 86: 143-150. doi: 10.1016/j.jpba.2013.07.046

102. Eweka A, Eweka A, Om'Iniabohs F. Histological studies of the effects of monosodium glutamate on the fallopian tubes of adult female wistar rats. Ann Biomed Sci. 2011; 2: 146-9. doi: 10.4314/abs.v9i1.66569

103. Fei X, Zhang X, Wang Q, Li J, Shen H, Wang X, et al. Xijiao dihuang decoction alleviates ischemic brain injury in MCAO rats by regulating inflammation, neurogenesis, and angiogenesis. Evidence-based Complement Altern Med. 2018; 2018(3): 1-12. doi: 10.1155/2018/5945128

104. Ahmed ME, Tucker D, Dong Y, Lu Y, Zhao N, Wang R, et al. Methylene Blue promotes cortical neurogenesis and ameliorates behavioral deficit after photothrombotic stroke in rats. Neuroscience. 2016; 336: 39-48. doi: 10.1016/j.neuroscience.2016.08.036

105. Tracey KJ. Reflex control of immunity. Nat Rev Immunol. 2009; 9 ; $418-428$.

106. Tracey KJ. The inflammatory reflex. Nature. 2002; 420: 853-859. doi 10.1038 /nature01321

107. Meisel C, Schwab JM, Prass K, Meisel A, Dirnagl U. Central nervous system injury-induced immune deficiency syndrome. Nat Rev Neurosci. 2005; 6: 775-786. doi: 10.1038/nrn1765

108. Cai PY, Bodhit A, Derequito R, Ansari S, Abukhalil F, Thenkabail $\mathrm{S}$, et al. Vagus nerve stimulation in ischemic stroke: Old wine in a new bottle. Front Neurol. 2014; 5: 107. doi: 10.3389/fneur.2014.00107

109. Townsend MK, Clish CB, Kraft P, Wu C, Souza AL, Deik AA, et al. Reproducibility of metabolomic profiles among men and women in 2 large cohort studies. Clin Chem. 2013; 59(11): 1657-67. doi: 10.1373/ clinchem.2012.199133

110. Dasgupta P, Rastogi S, Pillai S, Ordonez-Ercan D, Morris M, Haura E, et al. Nicotine induces cell proliferation by -arrestin-mediated activation of Src and Rb-Raf-1 pathways. J Clin Invest. 2006; 116: 2208-2217. doi: 10.1172/jci28164c1

111. Waite KA, Eng C. REVIEW ARTICLE Protean PTEN: Form and Function. Am J Hum Genet. 2002; 70: 829-44. doi: 10.1086/340026

112. Koh PO. Ferulic acid attenuates the down-regulation of MEK/ERK/ p90RSK signaling pathway in focal cerebral ischemic injury. Neurosci Lett. 2015; 588: 18-23. doi: 10.1016/j.neulet.2014.12.047

113. Ji B, Geng P, Liu JG, Shi DZ, Wang YY. Effects of active components extracted from Qixue Bingzhi Recipe on proliferation of vascular smooth muscle cells and expressions of platelet-derived growth factor and its receptor genes. J Chinese Integr Med. 2006; 4(1): 30-4. doi: 10.3736/jcim 20060109

114. Sheu JR, Kan YC, Hung WC, Ko WC, Yen MH. Mechanisms involved in the antiplatelet activity of tetramethylpyrazine in human platelets. Thromb Res. 1997; 88: 259-70. doi: 10.1016/S0049-3848(97)00253-3

115. Kong X, Su X, Zhu J, Wang J, Wan H, Zhong M, et al. Neuroprotective effect of buyang huanwu decoction on rat ischemic/reperfusion brain damage by promoting migration of neural precursor cells. Rejuvenation Res. 2014; 17: 264-75. doi: 10.1089/rej.2013.1468

116. Zhang WJ, Wojtaa J, Binder BR. Regulation of the fibrinolytic potential of cultured human umbilical vein endothelial cells: Astragaloside IV downregulates plasminogen activator inhibitor-1 and upregulates tissue-type plasminogen activator expression. J Vasc Res. 1997; 34: 273-80. doi: 10.1159/000159234

117. Liu B, Luo C, Zheng Z, Xia Z, Zhang Q, Ke C, et al. Shengui Sansheng San extraction is an angiogenic switch via regulations of AKT/ mTOR, ERK1/2 and Notch1 signal pathways after ischemic stroke Phytomedicine. 2018; 44: 20-31. doi: 10.1016/j.phymed.2018.04.025

118. Li LJ, Huang Q, Zhang N, Wang G Bin, Liu YH. miR-376b-5p regulates angiogenesis in cerebral ischemia. Mol Med Rep. 2014; 10: 527-535. doi: $10.3892 / \mathrm{mmr} .2014 .2172$

119. Li L, Saliba P, Reischl S, Marti HH, Kunze R. Neuronal deficiency of HIF prolyl 4-hydroxylase 2 in mice improves ischemic stroke recovery in an HIF dependent manner. Neurobiol Dis. 2016; 91: 221-3. doi: 10.1016/j.nbd.2016.03.018

120. Kume T. Ligand-dependent notch signaling in vascular formation. Adv Exp Med Biol. 2012; 727: 210-222. doi: 10.1007/978-1-4614-0899-4_16

121. Cai Z, Zhao B, Deng Y, Shangguan S, Zhou F, Zhou W, et al. Notch signaling in cerebrovascular diseases (Review). Mol Med Rep. 2016; 14(4): 2883-98. doi: 10.3892/mmr.2016.5641
122. Sewduth R, Santoro MM. "Decoding” angiogenesis: New facets controlling endothelial cell behavior. Front Physiol. 2016; 7: 306. doi: 10.3389/fphys.2016.00306

123. Zhang X, Zhang F, Kong D, Wu X, Lian N, Chen L, et al. Tetramethylpyrazine inhibits angiotensin II-induced activation of hepatic stellate cells associated with interference of platelet-derived growth factor $\beta$ receptor pathways. FEBS J. 2014; 281: 2754-2768. doi: 10.1111/ febs. 12818

124. Michan S, Sinclair D. Sirtuins in mammals: Insights into their biological function. Biochem J. 2007; 404: 1-13. doi: 10.1042/BJ20070140

125. Hu T, Chen Y, Jiang Q, Lin J, Li H, Wang P, et al. Overexpressed eNOS upregulates SIRT1 expression and protects mouse pancreatic $\beta$ cells from apoptosis. Exp Ther Med. 2017; 14: 1727-1731. doi: 10.3892/ etm.2017.4669

126. Lee IC, Ho XY, George SE, Goh CW, Sundaram JR, Pang KKL, et al. Oxidative stress promotes SIRT1 recruitment to the GADD34/PP1a complex to activate its deacetylase function. Cell Death Differ. 2018; 25: 255-267. doi: 10.1038/cdd.2017.152

127. Potente M, Ghaeni L, Baldessari D, Mostoslavsky R, Rossig L, Dequiedt F, et al. SIRT1 controls endothelial angiogenic functions during vascular growth. Genes Dev. 2007; 21: 2644-2658. doi: 10.1101/ gad.435107

128. Dong WP, Li NL, Gao DK, Zhen HN, Zhang X, Li FF. Resveratrol attenuates ischemic brain damage in the delayed phase after stroke and induces messenger RNA and protein express for angiogenic factors. J Vasc Surg. 2008; 48: 709-14. doi: 10.1016/j.jvs.2008.04.007

129. Ota H, Eto M, Ogawa S, Iijima K, Akishita M, Ouchi Y. Sirt1/eNOS axis as a potential target against vascular senescence, dysfunction and atherosclerosis. J Atheroscler Thromb. 2010; 17: 431-5. doi: 10.5551/ jat.3525

130. Al Sabti H. Therapeutic angiogenesis in cardiovascular disease. J Cardiothorac Surg. 2007; 2: 49. doi: 10.1186/1749-8090-2-49

131. Chen L, Chen X, Xing S, Zhang J, Li J, Dang C, et al. Tongxinluo attenuates neuronal loss and enhances neurogenesis and angiogenesis in the ipsilateral thalamus and improves neurological outcome after focal cortical infarction in hypertensive rats. Restor Neurol Neurosci. 2014; 52: 533-546. doi: 10.3233/RNN-140403

132. Meng Z, Li M, He Q, Jiang S, Zhang X, Xiao J, et al. Ectopic expression of human angiopoietin-1 promotes functional recovery and neurogenesis after focal cerebral ischemia. Neurosci. 2014; 267: 135-146. doi: 10.1016/j.neuroscience.2014.02.036

133. Doeppner TR, Kaltwasser B, Kuckelkorn U, Henkelein P, Bretschneider E, Kilic E, et al. Systemic Proteasome Inhibition Induces Sustained Poststroke Neurological Recovery and Neuroprotection via Mechanisms Involving Reversal of Peripheral Immunosuppression and Preservation of Blood-Brain-Barrier Integrity. Mol Neurobiol. 2016; 53: 6332-6341. doi: 10.1007/s12035-015-9533-3

134. Shi S, Xie J, Zhong J, Lin S, Zhang T, Sun K, et al. Effects of low oxygen tension on gene profile of soluble growth factors in co-cultured adipose-derived stromal cells and chondrocytes. Cell Prolif. 2016; 49: 341-351. doi: 10.1111/cpr.12259

135. Shi S, Lin S, Li Y, Zhang T, Shao X, Tian T, et al. Effects of tetrahedra DNA nanostructures on autophagy in chondrocytes. Chem Commun. 2018; 54: 1327-1330. doi: 10.1039/c7cc09397g

136. Shen J, Zhu Y, Yu H, Fan ZX, Xiao F, Wu P, et al. Buyang Huanwu decoction increases angiopoietin-1 expression and promotes angiogenesis and functional outcome after focal cerebral ischemia. J Zhejiang Univ Sci B. 2014; 15: 272-80. doi: 10.1631/jzus.B1300166

137. Choi JK, Dedeoglu A, Jenkins BG. Application of MRS to mouse models of neurodegenerative illness. NMR Biomed. 2007; 20: 216-37. doi: $10.1002 / \mathrm{nbm} .1145$

138. Wang HZ, Wang L, Zhang N, Zhang Q, Zhao H, Zhang QX. Houshiheisan compound prescription protects neurovascular units after cerebral ischemia. Neural Regen Res. 2014; 9: 741-8. doi: $10.4103 / 1673-5374.131580$

139. Kalkan Oğuzhanoğlu N, Sözeri Varma G, Karadağ F, Tümkaya S, Efe M, Kiroğlu Y. Prefrontal cortex neurochemical metabolite levels in major depression and the effects of treatment: An1HMRS study. Turk Psikiyatr Derg. 2014; 25: 75-83.

140.Zhang J, Zou H, Zhang Q, Wang L, Lei J, Wang Y, et al. Effects of Xiaoshuan enteric-coated capsule on neurovascular functions assessed by quantitative multiparametric MRI in a rat model of permanent cerebral ischemia. BMC Complement Altern Med. 2016; 16: 198. doi: $10.1186 / s 12906-016-1184-z$ 